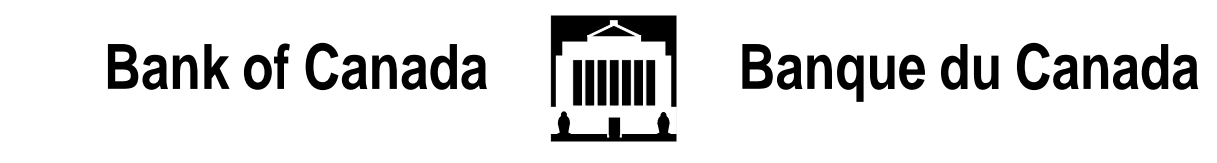

Working Paper 2002-5 / Document de travail 2002-5

\title{
The Effects of Bank Consolidation on Risk Capital Allocation and Market Liquidity
}


ISSN 1192-5434

Printed in Canada on recycled paper 
Bank of Canada Working Paper 2002-5

February 2002

\title{
The Effects of Bank Consolidation on Risk Capital Allocation and Market Liquidity
}

by

\author{
Chris D'Souza ${ }^{1}$ and Alexandra Lai ${ }^{2}$ \\ ${ }^{1}$ Financial Markets Department \\ ${ }^{2}$ Monetary and Financial Analysis Department \\ Bank of Canada \\ Ottawa, Ontario, Canada K1A 0G9 \\ dsou@bankofcanada.ca \\ laia@bankofcanada.ca
}

The views expressed in this paper are those of the authors.

No responsibility for them should be attributed to the Bank of Canada. 



\section{Contents}

Acknowledgements. . . . . . . . . .

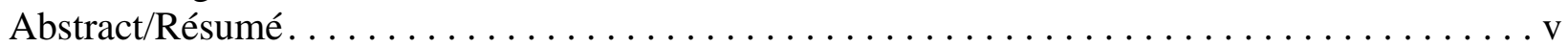

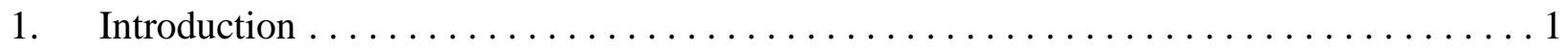

2. Capital Allocation in a Multi-Divisional Firm $\ldots \ldots \ldots \ldots \ldots \ldots \ldots \ldots \ldots$

2.1 First-best: centralized investment decisions $\ldots \ldots \ldots \ldots \ldots \ldots \ldots \ldots \ldots \ldots \ldots \ldots \ldots \ldots$

2.2 Delegated investment decisions $\ldots \ldots \ldots \ldots \ldots \ldots \ldots \ldots \ldots \ldots \ldots \ldots \ldots \ldots \ldots \ldots$

3. Model of the Dealership Market $\ldots \ldots \ldots \ldots \ldots \ldots \ldots \ldots \ldots \ldots \ldots \ldots$

3.1 Dealership market with identical market-makers $(\delta=1) \ldots \ldots \ldots \ldots \ldots$

3.2 Dealership market with heterogeneous market-makers $\ldots \ldots \ldots \ldots \ldots \ldots$

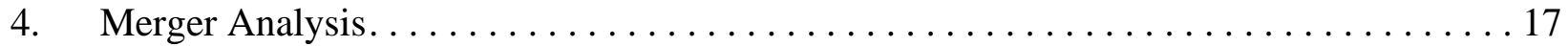

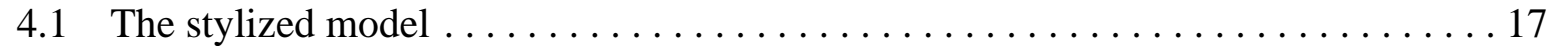

4.2 Effect of a merger on capital allocation $\ldots \ldots \ldots \ldots \ldots \ldots \ldots \ldots \ldots \ldots \ldots \ldots \ldots \ldots$

4.3 Effect of a merger on market liquidity $\ldots \ldots \ldots \ldots \ldots \ldots \ldots \ldots \ldots \ldots \ldots \ldots \ldots$

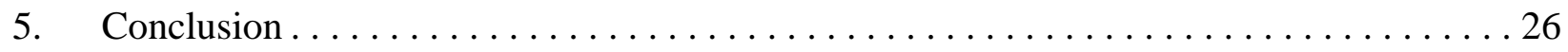

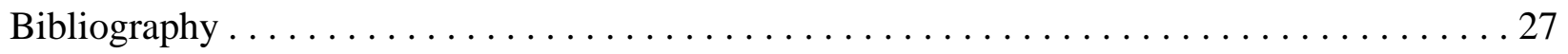

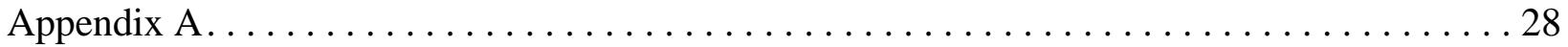




\section{Acknowledgements}

We thank Dave Bolder, Walt Engert, Gerald Goldstein, Toni Gravelle, Scott Hendry, Richard Lyons, Jamie MacKinnon, Sean O'Connor, and participants at the BIS Autumn Meeting for Central Bank Economists and the Bank of Canada's conference on Financial Market Structure and Dynamics, who provided helpful comments and suggestions. 


\section{Abstract}

This paper investigates the effects of financial market consolidation on risk capital allocation in a financial institution and the implications for market liquidity in dealership markets. We show that an increase in financial market consolidation can have ambiguous effects on liquidity in foreign exchange and government securities markets. The framework employed assumes that financial institutions use risk-management tools (for example, value-at-risk) in the allocation of risk capital. Capital is determined at the firm level and allocated among separate business lines, or divisions. The ability of market-makers to supply liquidity is influenced by their risk-bearing capacity, which is directly related to the amount of risk capital allocated to this activity. A model of inter-dealer trading is developed that is similar to the framework of Volger (1997). However, we allow for heterogeneity among dealers with respect to their risk-bearing capacity.

The allocation of risk capital within financial institutions has implications for the types of mergers among financial institutions that can be beneficial for market quality. This effect depends on the correlation among cash flows from business activities that the newly merged financial institution will engage in. A negative correlation between market-making and the new activities of a merged firm suggests the possibility of increased market liquidity. Our results suggest that, when faced

with a proposed merger between financial institutions, policy-makers and regulators would want to examine the correlations among division cash flows.

JEL classification: G28, G31, G34

Bank classification: Financial institutions; financial markets

\section{Résumé}

Les auteurs analysent les effets de l'intégration des marchés financiers sur la répartition du capital de risque au sein d'une institution financière ainsi que ses implications pour la liquidité des marchés de courtiers. Ils montrent qu'une intégration accrue des marchés financiers peut avoir une incidence ambiguë sur la liquidité des marchés des changes et des titres d'État. Leur cadre d'analyse part du principe que les institutions financières ont recours à des outils de gestion du risque (p. ex., la valeur exposée au risque) pour répartir le capital de risque. Le montant du capital est déterminé pour l'ensemble de l'institution et réparti parmi les différents secteurs d'activité. Le degré de liquidité que peuvent assurer les teneurs de marché est fonction de leur capacité à supporter des risques, laquelle dépend directement du montant de capital de risque alloué à la tenue de marché. Le modèle à l'aide duquel les auteurs formalisent le marché des courtiers 
s'apparente à celui de Volger (1997), mais la capacité de supporter des risques peut y varier d'un courtier à l'autre.

La répartition du capital de risque au sein d'une institution financière a une incidence sur les types de fusions susceptibles de favoriser la qualité du marché. Cette incidence dépend de la corrélation entre les flux de trésorerie liés aux activités commerciales dans lesquelles s'engagera l'institution financière nouvellement fusionnée. Une corrélation négative entre la tenue de marché et les nouvelles activités d'une société issue d'une fusion laisse entrevoir une amélioration possible de la liquidité du marché. Les auteurs en concluent que les décideurs et les organismes de réglementation pourraient avoir intérêt, lorsqu'ils examinent un projet de fusion d'institutions financières, à considérer les corrélations entre les flux de trésorerie des différents secteurs d'activité.

Classification JEL : G28, G31, G34

Classification de la Banque : Institutions financières; marchés financiers 


\section{Introduction}

Change in financial markets is ubiquitous. Historically, regulatory restrictions have often inhibited the ability of financial institutions operating in one area of the financial services industry to expand their product set into other areas. ${ }^{1}$ However, deregulation has allowed them to offer a broader range of banking, insurance, securities, and other financial services. Innovations in financial engineering and evolving market structures have altered the way financial markets and institutions operate. At the same time, deregulation in the industry has increased competition, prompting financial institutions to look for new profitable lines of business. Some financial institutions have found it advantageous to merge to generate higher returns through economies of scope or scale. The impact of consolidation on market liquidity, in particular liquidity in government securities and foreign exchange markets, is of increasing importance to policy-makers. Ensuring liquidity in the two markets is important to governments and central banks interested in maintaining or enhancing the functioning of those markets so that they can effectively implement fiscal and monetary policies. In Canada, policy-makers are concerned with the declining number of dealers in both Government of Canada fixed-income markets and foreign exchange markets, and they worry that increased consolidation among financial institutions will cause liquidity in those markets to fall.

This paper analyzes the impact of financial consolidation on market liquidity by studying the effects of consolidation on the risk-bearing capacity of market-makers, or dealers, in dealership markets. To carry out our analysis, two previously separate areas of research are bridged. The first, market microstructure theory, focuses on how market participants and the trading mechanism affect price discovery and market liquidity. ${ }^{2}$ The second, risk management, influences the way in which firms look at both the returns and risks of individual business operations. Our analysis traces the impact of a merger on the capital allocation decisions of the new merged financial institution and the resulting change in the behaviour of dealers.

Using a model in which a financial institution, which is henceforth referred to as a bank, allocates

\footnotetext{
${ }^{1}$ Until the 1990s, the Bank Act and provincial legislation enforced the separation of financial institutions in Canada into five principal groups: chartered banks, trust and loan companies, co-operative credit movements, insurance companies, and securities dealers. In the United States, the Glass-Steagall Act of 1933 sought to impose a rigid separation between commercial banking (deposit-taking and loan-making) and investment banking (underwriting, security-issuance). The act limited the ability of banks and securities firms to engage directly or indirectly in each other's activities.

${ }^{2}$ See O'Hara (1995) for a survey of the theoretical literature on market microstructure, and Madhavan (2000) for a survey of the empirical literature.
} 
risk capital across its business activities to satisfy a firm-wide capital requirement, we show that the optimal capital allocation conditions the risk-aversion of division managers and traders. This key result relates risk management by the bank to the behaviour of its market-makers in asset markets. The risk-bearing capacity of a dealership market depends on the number of market-makers present as well as their individual risk-aversion. Since market liquidity in dealership markets is determined by the inherent riskiness of the market and its risk-bearing capacity, capital allocation affects market liquidity by influencing the risk-aversion of market-makers.

We apply this framework to examine the effects of financial consolidation on market liquidity. We find that consolidation has an ambiguous effect on market liquidity. In particular, market liquidity can increase upon consolidation. Whether this happens depends on the correlation among the cash flows from the merged bank's division. This is in contrast with other results in the literature, which argue that market liquidity will necessarily deteriorate with consolidation. Those studies consider only the effects of a reduction in market-makers on risk-sharing, while our paper shows that the effect of a bank merger on liquidity will also depend critically on the risk-bearing capacities of the old and new banks. Therefore, policy-makers and regulators faced with a proposed merger between banks would want to examine the correlations among division cash flows. A negative correlation between market-making and the new activities of a merged firm suggests the possibility of increased market liquidity.

Capital allocation decisions are more complicated than a simple application of the Capital Asset Pricing Model (CAPM), since frictions exist in capital markets. Imperfect capital markets impose deadweight costs that must be covered by the cash flows of a business line if the business line is to be profitable. Froot and Stein (1998) and Perold (2001) model the capital structure decision by positing frictions in capital markets and/or in the internal management of firms that lead to deadweight costs. In Froot and Stein, firms engage in risk management to avoid ex post penalties resulting from a cash-flow shortfall. Perold, however, derives ex ante deadweight costs associated with actions undertaken by the firm to provide performance guarantees on its customer contracts through the purchase of insurance and a cash cushion. Both papers demonstrate that there is a trade-off between managing risk via ex ante capital structure policies and managing it via capital budgeting and hedging policies. Hence, the capital structure, hedging, and capital budgeting policies of a firm are interrelated and jointly determined. In a multi-divisional firm, risk-management tools are also 
used for performance evaluation. Specifically, risk capital allocation is an important component of determining the risk-adjusted rate of return and ultimately the economic value-added (EVA) of each business unit. Such calculations can then form the basis for incentive compensation. Stoughton and Zechner (1999) examine performance evaluation and managerial compensation issues, but we will abstract from those issues in this paper. In addition to the internal risk management that financial institutions engage in, regulators impose capital requirements on banks. Externalities from bank failures, risk-shifting in the presence of fixed premium deposit insurance, and the protection of uninformed investors who hold most of a bank's debt are the main justification for regulating bank capital. For all these reasons, financial institutions often maintain capital levels over and above the amounts they need to finance their operations.

Market liquidity is influenced by the way the market is structured. For example, most foreign exchange and government bond markets are characterized by price competition (quote-driven) among multiple dealers and inter-dealer trading, rather than by Cournot competition (order-driven), and the actions of the dealers in the public and inter-dealer markets provide much of the market liquidity. Such markets are referred to as dealership markets. This paper develops a dealership market model that is similar to the framework of Volger (1997). However, we allow for heterogeneity among dealers with respect to their risk-bearing capacity.

The paper is organized as follows. Section 2 presents the capital allocation model for a bank with multiple divisions. Section 3 analyzes a dealership market model in which dealers can be heterogeneous with respect to their risk-aversion. Section 4 examines the effects of financial consolidation on capital allocation and liquidity in the dealership market. Section 5 suggests implications for regulators and policy-makers, and for further research.

\section{Capital Allocation in a Multi-Divisional Firm}

Effective risk management promotes the stability of both financial institutions and industry by protecting the institution against market, credit, liquidity, operational, and legal risk. The primary means of protection is the financial institution's risk (or economic) capital. One goal of risk management is to determine the firm's optimal capital structure. This process involves estimating how much risk each business unit, or division, contributes to the total risk of the firm, and thus to overall 
capital requirements. Since investment decisions and risk exposures are determined at the division level, correlations between portfolios held by different divisions are externalities among units that create a need for centralized risk management. Hence, risk management in a multi-divisional firm also involves determining the capital charge to each division whose activities contribute to firm risk, to induce the appropriate risk-taking behaviour by division managers.

The framework that we use in this section is adapted from Stoughton and Zechner (1999). Consider an economy with $\mathrm{N}+1$ banks, indexed $i=0, . ., N .^{3}$ Each bank is engaged in a number of financial activities that generate income or cash flows. These activities are indexed by $j$. We denote the set of all possible financial activities by $J$. One activity that all banks participate in is market-making in a dealership market for a particular security. ${ }^{4}$ In this section, we analyze the problem of a bank that engages in a subset $K \subseteq J$ of activities, each of which generates cash flows to equity-holders. ${ }^{5}$ Each business line, $j$, is undertaken by a division, so we will denote the division by the same index, $j$.

Each division, $j$, has an expected cash flow determined by

$$
E\left(y_{j}\right)=\mu_{j}\left(\sigma_{j}^{2}\right), j \in K
$$

where $\sigma_{j}^{2}$ is the variance of cash flow from division $j$. It is assumed that more risk-taking by a division yields a higher expected return,

$$
\frac{\partial \mu_{j}}{\partial \sigma_{j}^{2}}>0, j \in K
$$

In addition, we assume that the function $\mu_{j}$ is strictly concave in $\sigma_{j}^{2}$ and that the Inada conditions hold, or

$$
\frac{\partial^{2} \mu_{j}}{\partial \sigma_{j}^{2}}<0,\left.\frac{\partial \mu_{j}}{\partial \sigma_{j}^{2}}\right|_{\sigma_{j}^{2}=0} \rightarrow \infty, \lim _{\sigma_{j}^{2} \rightarrow \infty} \frac{\partial \mu_{j}}{\partial \sigma_{j}^{2}}=0, j \in K .
$$

To simplify the analysis without loss of generality, investment activities are assumed to require zero cash outlay, or cash flows are defined after the appropriate interest costs. Furthermore, for any $j, h \in J$, the correlation between project $j$ 's and project $h$ 's cash flows is given by $\rho_{h j}$.

\footnotetext{
${ }^{3}$ Later, we analyze the case in which a merger occurs and $N$ banks remain in the economy.

${ }^{4}$ This may be a foreign exchange, fixed-income, or equity market.

${ }^{5}$ We will drop, for now, the index $i$ corresponding to the $N+1$ bank. In later sections of the paper, the index will be brought back into our notation.
} 
The opportunity cost of equity capital, $r>0$, is assumed to be constant and identical across banks. Financial institutions must allocate the scarce equity capital without violating regulatory constraints. A bank's equity capital requirement is determined as a fixed proportion of the risk of its portfolio, as measured by the variance of its total cash flows,

$$
C \geq \alpha \sigma_{p}^{2}, \alpha>0
$$

The bank's overall risk, $\sigma_{p}^{2}$, can be expressed as

$$
\sigma_{p}^{2}=\sum_{j \in K} \sigma_{j}^{2}+\sum_{h \in K} \sum_{j \in K, j \neq h,} \rho_{h j} \sigma_{h} \sigma_{j}
$$

The bank's objective function is to maximize the net present value of cash flows, taking into account the opportunity cost of capital. This is equivalent to maximizing the EVA or the contribution to shareholder value, where

$$
\mathrm{EVA}=\sum_{j \in K} \mu_{j}-r C
$$

\subsection{First-best: centralized investment decisions}

Before we examine the problem of allocating capital across divisions in a delegated environment, we first derive the solution to the bank's centralized problem. Continuing with our analysis of a bank with multiple divisions, indexed by $j \in K$, the centralized problem is

$$
\begin{gathered}
\max _{\left\{\sigma_{j}\right\}_{j \in K}} \sum_{j \in K} \mu_{j}\left(\sigma_{j}^{2}\right)-r C \\
\text { s.t. }
\end{gathered}
$$

where $\sigma_{p}^{2}$ is defined in (3). Since capital is costly, the constraint in the maximization problem is always satisfied with equality.

The first-order conditions (for an interior optimum) are

$$
\frac{\partial \mu_{j}\left(\hat{\sigma}_{j}^{2}\right)}{\partial \sigma_{j}^{2}}=r \alpha\left[1+\sum_{h \neq j, h \in K} \rho_{h j}\left(\frac{\hat{\sigma}_{h}^{2}}{\hat{\sigma}_{j}^{2}}\right)^{1 / 2}\right], j \in K
$$

where $\hat{\sigma}_{j}, j \in K$ is the optimal risk level for division $j$.

The right-hand-side of the above equation is just the marginal contribution to the overall risk of the bank by division $j$ 's activities multiplied by the cost of capital. At a given risk level, $\sigma_{j}^{2}$, 
division $j$ 's marginal contribution to the overall risk of the bank is

$$
\frac{\partial \alpha \sigma_{p}^{2}}{\partial \sigma_{j}^{2}}=\alpha\left[1+\sum_{h \neq j, h \in K} \rho_{h j} \frac{\sigma_{h}}{\sigma_{j}}\right], j \in K .
$$

Intuitively, investment (in terms of risk undertaken) will occur up to the point where the marginal increase in expected returns from activities by division $j$ is balanced by the marginal cost of risk undertaken by that division.

\subsection{Delegated investment decisions}

In an environment where investment decisions are delegated to each division, the bank's problem is one of allocating the appropriate amount of risk capital across divisions to maximize the bank's EVA. It is straightforward to determine the capital allocation function that implements the firstbest solution to the delegated problem. Suppose that the bank establishes a capital allocation rule for each division, $T_{j}, j \in K$. The formal delegation problem can be written as

$$
\begin{aligned}
\max _{\left\{T_{j}\right\}_{j \in K}} & \sum_{j \in K}\left[\mu_{j}\left(\sigma_{j}^{2}\right)-r C-U_{j}\right] \\
\text { s.t. } & \sigma_{j}^{2} \in \arg \max _{\sigma^{2}} \mu_{j}\left(\sigma^{2}\right)-r T_{j}\left(\sigma_{j}^{2}\right), j \in K, \\
& C \geq \alpha \sigma_{p}^{2},
\end{aligned}
$$

where $U_{j}$ denotes the compensation that the firm transfers to division managers. This compensation function is designed so that each division undertakes optimal investment decisions and it is assumed to consist of a fixed (salary) component, $S_{j}$, and a performance component in the form of a share of the EVA generated by the division. The division's EVA is, in turn, defined as the mean return from the division's project adjusted for the appropriate capital charge, $r T_{j}$. That is,

$$
U_{j}=\tau\left[\mu_{j}-r T_{j}\right]+S_{j}, j \in K
$$

This compensation scheme induces each division to solve the problem

$$
\max _{\sigma_{j}^{2}} \mu_{j}\left(\sigma_{j}^{2}\right)-r T_{j}, j \in K
$$

which yields constraint (9) in the bank's delegation problem. We present the solution to the delegation problem and its implication in the following proposition. 
Proposition 1 The optimal capital allocation function to each divison $j, j \in K$, is a linear function of the risk undertaken by the division:

$$
T_{j}\left(\sigma_{j}^{2}\right)=\theta_{j} \sigma_{j}^{2}, j \in K
$$

where

$$
\theta_{j}=\alpha\left[1+\sum_{h \neq j, h \in K} \rho_{h j}\left(\frac{\hat{\sigma}_{h}^{2}}{\hat{\sigma}_{j}^{2}}\right)^{1 / 2}\right] .
$$

This capital allocation function conditions division managers' risk-aversion so that, by maximizing their utility, they behave like risk-averse agents, with exponential utility functions and risk-aversion parameters given by

$$
\gamma_{j}=r \theta_{j}, j \in K
$$

in the presence of normally distributed cash flows.

Proof: See Appendix A.1.

The optimal capital allocation to a division is thus proportional to the risk the division undertakes, where risk is measured by the variance of the cash flow it generates. One can think of this as a charge to the division for the risk imposed on the bank by the division's activities. More importantly, this proposition relates the risk management of a bank to the behaviour of its dealers in the bank's trading activities. We elaborate on this point in the next section where a dealership market model is presented.

\section{Model of the Dealership Market}

Liquidity is an important dimension of all financial markets. ${ }^{6}$ For example, government securities markets perform several important functions that hinge on the fact that they are very liquid. It is the market in which governments raise funds and is thus of particular interest to central banks with fiscal agency responsibilities. Furthermore, because of their virtually riskless nature, government securities serve as the pricing benchmark and hedging vehicle for other fixed-income securities. While market liquidity is a concept that is difficult to measure or define because of its

\footnotetext{
${ }^{6}$ The discussion of liquidity is taken from Gravelle $(1999,2001)$.
} 
multi-dimensional nature, most market participants would agree on the following characterization: a liquid market is one in which large transactions can be completed quickly with little impact on prices. $^{7}$ The various dimensions of liquidity also tend to interact. ${ }^{8}$ In this paper, we focus on bid-ask spreads as a measure of liquidity.

In this section, we develop a model of the dealership market in which banks provide marketmaking services. Each bank's market-making activity is carried out by a dealer whose risk-taking behaviour is constrained by the bank's capital allocation. This allows us to study how the capital allocation decisions by individual banks impact market liquidity. We then apply this framework to a merger between two banks by first examining how capital allocation is affected by the merger and the consequences of that for market liquidity.

Consider a security that trades in a dealership market with $\mathrm{N}+1$ market-makers (or dealers). The security is traded at price $p$ between dealers and outside investors in the public market, and at price $p_{d}$ among dealers in a separate inter-dealer market. The exogenously given liquidation value of the security is denoted by $v$, a random variable that is normally distributed with zero mean and standard deviation $\sigma_{v}$. We assume that no market participant has private information about the future liquidation value of the traded security. There is one investor in the market who trades a quantity, $w$, the realization of a random variable that is independent of the asset's liquidation value, $v$, and distributed with zero mean and standard deviation $\sigma_{w}$. By convention, $w>0$ denotes an investor's buy order and $w<0$ a sell order. We consider one trading period where trade takes place in two stages.

In Stage 1, all dealers simultaneously quote a price schedule over customer orders, $w$, in the public market. The investor observes the quotes of all the competing dealers and submits the whole order, $w$, to the dealer quoting the best price. It is a defining characteristic of dealership markets that market-makers compete for the whole order. We assume that each dealer starts with a zero

\footnotetext{
${ }^{7}$ In the literature, market liquidity is typically defined over four dimensions: immediacy, depth, width (bid-ask spread), and resiliency. Immediacy refers to the speed with which a trade of a given size at a given width is completed. Depth refers to the maximum size of trade that can be carried out for any given bid-ask spread. Width refers to the cost of providing liquidity, with narrower spreads implying greater liquidity. Resiliency refers to how quickly imbalances in transaction flows dissipate. An imbalance in transaction flows means that there is a one-way market, or prices are gapping. If imbalances tend to persist, or when imbalances do not tend to generate counterbalancing order flow (once prices have moved enough to attract this counterbalancing order flow), the market is not resilient.

${ }^{8}$ For example, width will generally increase with the size of a given trade, or, for a given bid-ask spread, all transactions under a given size can be executed immediately with no movement in the price or spread.
} 
inventory position that is observable to all dealers. ${ }^{9}$ Bargaining between investors and marketmakers is resolved by assuming that market-makers compete à-la-Bertrand. That is, all bargaining power is on the investor's side.

Trading between market-makers to reallocate inventories takes place in Stage 2. Once an investor gives the whole order to one of the $N+1$ competing dealers, that particular dealer's inventory changes by $-w$. This dealer now has an incentive to trade in the inter-dealer market to reduce his risk exposure. Hence, inter-dealer trading allows dealers to risk-share. Dealers are assumed to behave as strategic competitors by submitting their demand functions in the inter-dealer market. That is, they take into account the effect their quantities are expected to have on the market-clearing price. The equilibrium concept we employ is that of a non-competitive rational expectations Nashequilibrium in demands (Kyle 1989). The security will be liquidated at the end of the inter-dealer trading in Stage 2.

The $\mathrm{N}+1$ dealers are indexed by $i=0, \ldots, N$. Each dealer behaves like a risk-averse agent with a coefficient of absolute risk-aversion given by $\gamma_{i} \cdot{ }^{10}$ Specifically, Dealer $i$ with risk-aversion parameter $\gamma_{i}$ maximizes the exponential utility function

$$
U\left(\pi_{i}\right)=-e^{-\gamma_{i} \pi_{i}}
$$

where $\pi_{i}=v\left(x_{i}-w\right)+p w-p_{d} x_{i}$ is the profit of Dealer $i$ who has an order from the investor, while $\pi_{i}=v x_{i}-p_{d} x_{i}$ is the profit of a dealer who does not get a customer order; $x_{i}$ is the demand of Dealer $i$ in the inter-dealer market; $p$ is the price at which the customer order is transacted; and $p_{d}$ is the price that prevails in the inter-dealer market.

We will solve the model under two different scenarios. In the first, we assume that dealers have identical risk-aversion, $\gamma$. In the second, we assume that dealers are one of two types: Type 1 dealers have risk-aversion $\gamma_{1}=\delta \gamma, \delta>0$ and Type 2 dealers have risk-aversion $\gamma_{2}=\gamma$. There are $N_{1}$ Type 1 dealers and $N_{2}$ Type 2 dealers. Naturally, $N_{1}+N_{2}=N+1$.

Later, when we analyze the effects of a merger between two banks (and, consequently, two dealers), the starting point is a market with identical dealers. This is the case when potentially

\footnotetext{
${ }^{9}$ Allowing for different initial inventories only complicates the analysis without qualitatively affecting our merger analysis results in the next section.

${ }^{10}$ In our framework, dealers' risk-aversion is determined by the amount of risk capital allocated to market-making in that security by the financial institutions that own the dealers.
} 
differentiated banks allocate the same amount of capital to market-making. When two of those banks merge, we allow for the case that the merged entity engages in a different set of activities, thus allocating risk capital differently across business lines. To this end, we will need an analysis of a dealership market with heterogeneous dealers.

\subsection{Dealership market with identical market-makers $(\delta=1)$}

In this section, dealers have an identical coefficient of absolute risk-aversion, given by $\gamma$. We solve the model by backward induction. That is, we first solve Stage 2 of the model for a symmetric equilibrium in the inter-dealer market, taking the equilibrium price in the public market as given. Then we solve Stage 1 of the model for the equilibrium reserve prices (the price that leaves the dealer indifferent between getting the customer order and not getting it) in the public market. For reservation prices that differ, the equilibrium price in the public market is given by the second-best reservation price that is quoted by the dealer with the best reservation price. When all dealers have the same reservation price, they each quote their reservation prices and receive the customer order with equal probability.

\subsubsection{Equilibrium in the inter-dealer market (Stage 2)}

We simplify the analysis by assuming that the inter-dealer market is a call market. All marketmakers submit their orders simultaneously to an inter-dealer broker, which executes the set of multilateral transactions at one market-clearing price.

A symmetric linear equilibrium in the inter-dealer market is obtained if the demand schedules of each Dealer $i$ can be written as

$$
x_{i}=\alpha-\beta p_{d}+\eta w_{i}, \quad i=0, . ., N
$$

Proposition 2 There exists a linear equilibrium in the inter-dealer market in which marketmakers' demand are given by (15). The parameters are given by

$$
\alpha=0, \quad \beta=\frac{N-1}{N \Psi}, \quad \eta=\frac{N-1}{N},
$$


where $\Psi=\gamma \sigma_{v}^{2}$. The equilibrium price in the inter-dealer market is

$$
p_{d}=\frac{\Psi}{N+1} w
$$

Proof: See Appendix A.2.

The equilibrium price in the inter-dealer market depends on the size of the investor's order. $\eta$ is the proportion of the investor's order that a dealer passes on in the inter-dealer round of trading, and hence is a measure of risk-sharing. It is increasing in $N$. Therefore, risk-sharing improves as the total number of dealers in the market increases and the inter-dealer market becomes more competitive.

Using the fact that $w_{i}=w$ if Dealer $i$ had the customer order and $w_{i}=0$ otherwise, demands and inventories after inter-dealer trade are

$$
\begin{aligned}
& x_{i}= \begin{cases}\frac{N-1}{(N+1)} w & \text { if } w_{i}=w \\
-\frac{N-1}{N(N+1)} w & \text { if } w_{i}=0\end{cases} \\
& I_{i}= \begin{cases}\frac{N-1}{(N+1)} w-w=-\frac{2}{N+1} w & \text { if } w_{i}=w \\
-\frac{N-1}{N(N+1)} w & \text { if } w_{i}=0 .\end{cases}
\end{aligned}
$$

Notice that risk-sharing is not perfect in this model. Since dealers are ex ante identical, perfect risk-sharing implies that all dealers will end up with identical inventory levels after inter-dealer trade, or $I^{*}=-\frac{w}{N+1}$. However, $\left|I_{i}\right|>\left|I^{*}\right|$ if $w_{i}=w$ and $\left|I_{i}\right|<\left|I^{*}\right|$ if $w_{i}=0$.

Perfect risk-sharing does not occur because of imperfect competition in the inter-dealer market. That is, dealers have the incentive to restrict the quantity they trade in the inter-dealer market relative to what they would trade if the inter-dealer market was competitive. Note that perfect risk-sharing will result if $N \rightarrow \infty$.

\subsubsection{Equilibrium in the public market (Stage 1)}

To solve for the equilibrium in the public order market, we first determine each dealer's reservation quotes, in anticipation of inter-dealer trading in the next stage. The dealer with the best reservation price receives the public order by quoting the second-best reservation price. Recall that Dealer $i$ 
with the public order has a final inventory $-\frac{2}{N+1} w$, while a dealer with no public order has a final inventory $-\frac{N-1}{N(N+1)} w$.

Denote Dealer $i$ 's reservation price by $p_{i}^{r}, i=0, . ., N$. Dealer $i$, who receives the public order at the reservation price $p_{i}^{r}$, has an expected utility

$$
\begin{aligned}
E U_{i}^{w} & =p_{i}^{r} w-p_{d} x_{i}-\frac{\Psi}{2}\left(\frac{2}{N+1} w\right)^{2} \\
& =p_{i}^{r} w-\frac{(N-1) \Psi}{(N+1)^{2}} w^{2}-\frac{\Psi}{2}\left(\frac{2}{N+1} w\right)^{2} ;
\end{aligned}
$$

otherwise, that dealer's expected utility is

$$
\begin{aligned}
E U_{i}^{0} & =-p_{d} x_{i}-\frac{\Psi}{2}\left(\frac{N-1}{N(N+1)} w\right)^{2} \\
& =\frac{(N-1) \Psi}{N(N+1)^{2}} w^{2}-\frac{\Psi}{2}\left(\frac{N-1}{N(N+1)} w\right)^{2} .
\end{aligned}
$$

At the reservation price $p_{i}^{r}$, Dealer $i$ is indifferent between getting the public order and not getting it. Equating $E U_{i}^{w}=E U_{i}^{0}$ and simplifying, we get Dealer $i$ 's reservation price, given in the next proposition.

Proposition 3 For $N>0$, the equilibrium price in the public market is

$$
p=\frac{(2 N-1) \Psi}{2 N^{2}} w
$$

and the market bid-ask spread for a customer order of size $|w|$ is

$$
s=\frac{(2 N-1) \Psi}{N^{2}}|w|
$$

Since all dealers are identical, they quote the same price (equal to their reservation price) and have equal chances of receiving the public order. The market bid-ask spread for an order of size $|w|$ is just $s=2|p|$. If dealers are risk-neutral $\left(\Psi=\gamma \sigma_{v}^{2}=0\right)$, the equilibrium price is equal to the expected value of the security, which is normalized to zero. For risk-averse dealers and multiple dealers, $N>0$, the equilibrium price is increasing in the size of the customer order and decreasing in $N$. The larger the size of the customer order, the higher the risk premium required by dealers to absorb this quantity. An increase in the number of competing dealers leads to better risk-sharing and hence a lower risk premium is required. Thus, market liquidity, as measured by the bid-ask spread, increases with the number of dealers, $N$, but decreases with risk-aversion, $\Psi$, and the size of the market order, $|w|$. 


\subsection{Dealership market with heterogeneous market-makers}

In this section, there are two types of dealers: Type 1 dealers have risk-aversion $\gamma_{1}=\delta \gamma, \delta>0$, and Type 2 dealers have risk-aversion $\gamma_{2}=\gamma$. There are $N_{1}$ Type 1 dealers and $N_{2}$ Type 2 dealers, where $N_{1}+N_{2}=N+1$. We begin by characterizing the equilibrium for the case where $N_{1}$ and $N_{2}$ can take any values, but we solve explicitly for the equilibrium with only one Type 1 dealer and $N$ Type 2 dealers. This minimal amount of heterogeneity is all we need to perform the merger analysis that comprises the next part of this paper.

\subsubsection{Equilibrium in the inter-dealer market (Stage 2)}

Let the set of Type 1 dealers be denoted by $\chi_{1}$ and the set of Type 2 dealers be denoted by $\chi_{2}$. From this point on, we will denote an arbitrary Type 1 dealer by $i$ and an arbitrary Type 2 dealer by $j$. A linear equilibrium in the inter-dealer market is obtained if the demand schedules of Dealer $i$ of Type 1 and Dealer $j$ of Type 2 can be written as

$$
\begin{array}{cc}
x_{i}=\alpha_{1}-\beta_{1} p_{d}+\eta_{1} w_{i}, & \forall i \in \chi_{1} \\
x_{j}=\alpha_{2}-\beta_{2} p_{d}+\eta_{2} w_{j}, & \forall j \in \chi_{2} .
\end{array}
$$

Proposition 4 (General case) There exists a linear equilibrium in the inter-dealer market in which the market-makers' demand is given by (26) and (27). The parameters are given implicitly by

$$
\begin{gathered}
\alpha_{1}=\alpha_{2}=0, \quad \eta_{1}=\delta \Psi \beta_{1}, \quad \eta_{2}=\Psi \beta_{2}, \\
\beta_{1}=\frac{\left(N_{1}-1\right) \beta_{1}+N_{2} \beta_{2}}{1+\delta \Psi\left[\left(N_{1}-1\right) \beta_{1}+N_{2} \beta_{2}\right]}=\frac{\bar{\beta}-\beta_{1}}{1+\delta \Psi\left(\bar{\beta}-\beta_{1}\right)}, \\
\beta_{2}=\frac{N_{1} \beta_{1}+\left(N_{2}-1\right) \beta_{2}}{1+\Psi\left(N_{1} \beta_{1}+\left(N_{2}-1\right) \beta_{2}\right)}=\frac{\bar{\beta}-\beta_{2}}{1+\Psi\left(\bar{\beta}-\beta_{2}\right)},
\end{gathered}
$$

where $\bar{\beta}=N_{1} \beta_{1}+N_{2} \beta_{2}$ and $\Psi=\gamma \sigma_{v}^{2}$. Denoting the type of dealer who received the customer order in Stage 1 by $y$, the equilibrium price in the inter-dealer market is

$$
\begin{aligned}
p_{d} & =\frac{\beta_{1} \delta \Psi w}{\bar{\beta}} & & \text { if } y \in \chi_{1} \\
& =\frac{\beta_{2} \Psi w}{\bar{\beta}} & & \text { if } y \in \chi_{2} .
\end{aligned}
$$


The proof of Proposition 4 follows the same steps as for Proposition 1. Note that the equilibrium inter-dealer price is lower if the dealer with the public order has lower risk-aversion. For $\delta<1$ $(\delta>1)$, a Type 1 dealer has lower (higher) risk-aversion than a Type 2 dealer. As well, the equilibrium inter-dealer price increases with the size of the customer order, $|w|$.

Although the solutions to the two equations for $\beta_{1}$ and $\beta_{2}$ are difficult to derive explicitly, we can characterize the solutions:

(i) $\beta_{1}, \beta_{2}$ and $\bar{\beta}$ are increasing in $\delta$.

(ii) $\beta_{1}-\beta_{2}>0$ and $\delta \Psi \beta_{1}-\Psi \beta_{2}<0$ for $N>2$ and $\delta<1$.

$\beta_{1}-\beta_{2}<0$ and $\delta \Psi \beta_{1}-\Psi \beta_{2}<0$ for $N>2$ and $\delta>1$.

(iii) $\beta_{1}, \beta_{2}$, and $\bar{\beta}$ are decreasing in $\Psi$.

(iv) Holding $N$ constant, $\beta_{1}, \beta_{2}$, and $\bar{\beta}$ are decreasing in $N_{1}$ if $\delta<1$ and increasing in $N_{1}$ if $\delta>1$.

For the special case of $N_{1}=1$, the explicit solutions for $\beta_{1}$ and $\beta_{2}$ are given in the next proposition. This special case is relevant when we analyze a merger between two banks, and hence two dealers.

Proposition 5 (Special case) For $N_{1}=1$ and $N>3$, there exists a linear equilibrium in the inter-dealer market in which the market-makers' demand is given by (26) and (27). The parameters are given implicitly by

$$
\begin{gathered}
\alpha_{1}=\alpha_{2}=0, \quad \eta_{1}=\delta \Psi \beta_{1}, \quad \eta_{2}=\Psi \beta_{2}, \\
\beta_{1}=\frac{N_{2} \beta_{2}}{1+\delta \Psi N_{2} \beta_{2}}, \\
\beta_{2}=\frac{\delta N_{2}^{2}+1-2 N_{2}(1+\delta)+\sqrt{\left[\delta N_{2}^{2}+1-2 N_{2}(1+\delta)\right]^{2}+4 \delta N_{2}\left(N_{2}-1\right)\left(2 N_{1}-2\right)}}{2 \delta N_{2}\left(N_{2}-1\right)},
\end{gathered}
$$

where $\Psi=\gamma \sigma_{v}^{2}$.

\subsubsection{Equilibrium in the public market (Stage 1)}

In this section, we carry through the assumption that $N_{1}=1$ and $N_{2}=N$. As before, we first determine each dealer's reservation quotes in the public market, in anticipation of inter-dealer 
trading in the next stage. Since there are two types of dealers, there will be two different reservation prices. The dealer with the best reservation price receives the public order by quoting the secondbest reservation price.

Let $p_{1}^{r}$ be the reservation price of the Type 1 dealer and $p_{2}^{r}$ be the reservation price of a Type 2 dealer.

Proposition 6 Let $\Psi_{1}=\delta \gamma \sigma_{v}^{2}$ and $\Psi_{2}=\gamma \sigma_{v}^{2}$. The Type 1 dealer has a reservation price given by

$$
p_{1}^{r}=\left\{\left(1-\frac{\beta_{1}}{\bar{\beta}}\right) \frac{\beta_{1}^{2} \Psi_{1}^{2}}{\bar{\beta}}+\frac{\beta_{1}}{2 \bar{\beta}^{2}} \beta_{2}^{2} \Psi_{2}^{2}\left(2-\beta_{1} \Psi_{1}\right)-\frac{\Psi_{1}}{2}\left[1-\left(1-\frac{\beta_{1}}{\bar{\beta}}\right), \beta_{1} \Psi_{1}\right]^{2}\right\} w
$$

while a Type 2 dealer has a reservation price given by

$$
p_{2}^{r}=\left\{\left(1-\frac{\beta_{2}}{\bar{\beta}}\right) \frac{\beta_{2}^{2} \Psi_{2}^{2}}{\bar{\beta}}+\frac{\beta_{2}}{2 \bar{\beta}^{2}} \beta_{1}^{2} \Psi_{1}^{2}\left(2-\beta_{2} \Psi_{2}\right)-\frac{\Psi_{2}}{2}\left[1-\left(1-\frac{\beta_{2}}{\bar{\beta}}\right) \beta_{2} \Psi_{2}\right]^{2}\right\} w
$$

if the winning dealer is a Type 1 dealer, and

$$
p_{2}^{r}=\left\{\left(1-\frac{\beta_{2}}{\bar{\beta}}\right) \frac{\beta_{2}^{2} \Psi_{2}^{2}}{\bar{\beta}}+\frac{\beta_{2}}{2 \bar{\beta}^{2}} \beta_{2}^{2} \Psi_{2}^{2}\left(2-\beta_{2} \Psi_{2}\right)-\frac{\Psi_{2}}{2}\left[1-\left(1-\frac{\beta_{2}}{\bar{\beta}}\right) \beta_{2} \Psi_{2}\right]^{2}\right\} w
$$

if the winning dealer is another Type 2 dealer.

We turn to numerical examples (Figure 1) to illustrate the following proposition, which lays out the equilibrium price in the public market.

Proposition 7 Assuming that $N \geq 3$, then the following is true.

(i) If $\delta<1$, the Type 1 dealer has the better reservation price, $p_{1}^{r}<p_{2}^{2}$. Hence, the equilibrium price is given by (35) and the Type 1 dealer receives the customer order.

(ii) If $\delta>1$, Type 2 dealers have the better reservation price, $p_{1}^{r}>p_{2}^{2}$. Hence, the equilibrium price is given by (34) and a Type 2 dealer receives the customer order.

In addition, the gap in the reservation prices between Type 1 and Type 2 dealers increases with the difference in their risk parameters. That is, the gap in reservation prices decreases with $\delta$ for $\delta<1$ and it increases with $\delta$ for $\delta>1$. Note that the two types are identical when $\delta=1$. 
Figure 1: Reservation prices for Type 1 and Type 2 dealers

a: Reservation prices by type, $\delta=0.5$

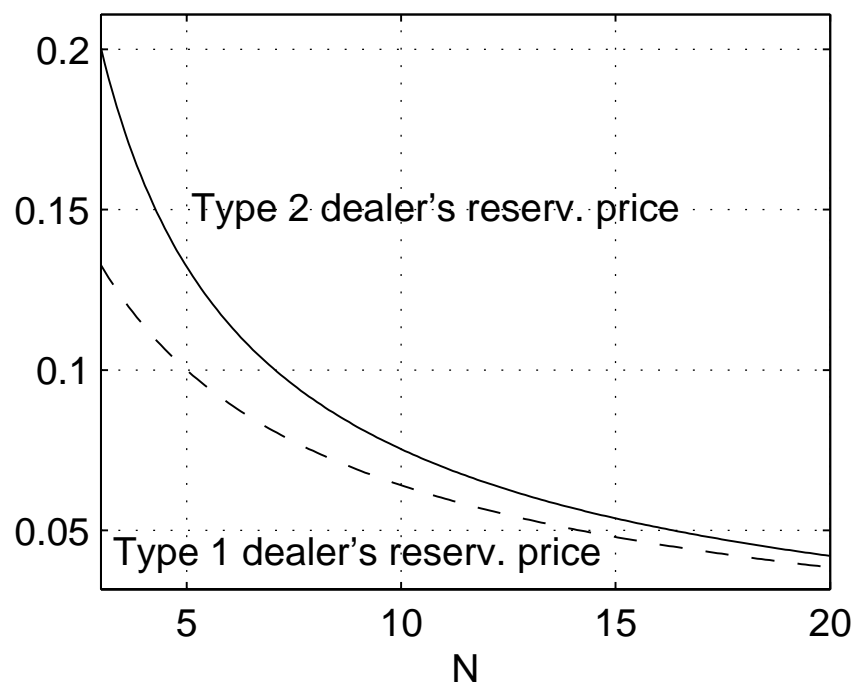

C: Reservation prices by type, $\delta=1.5$

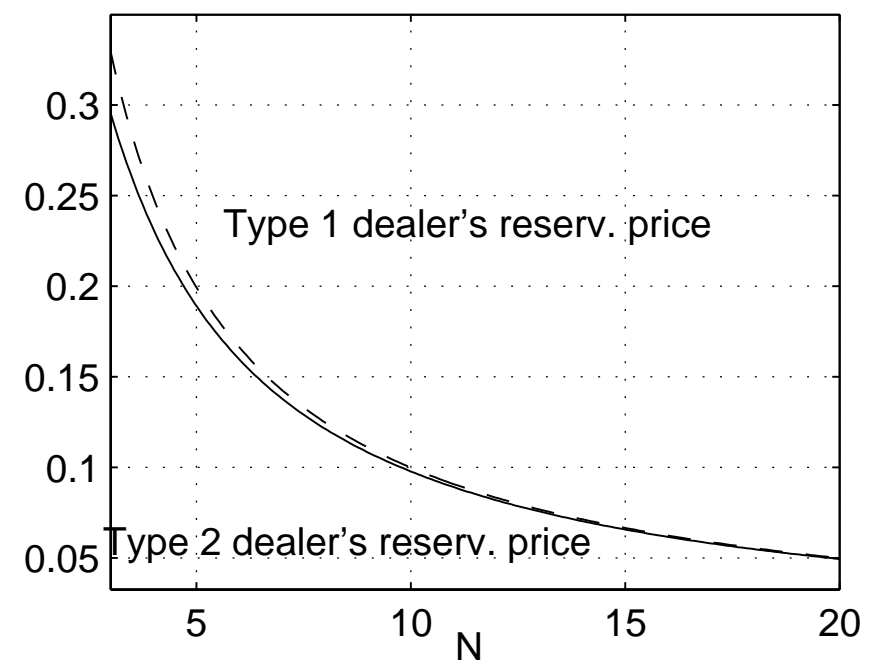

b: Reservation prices by type, $\delta=0.8$

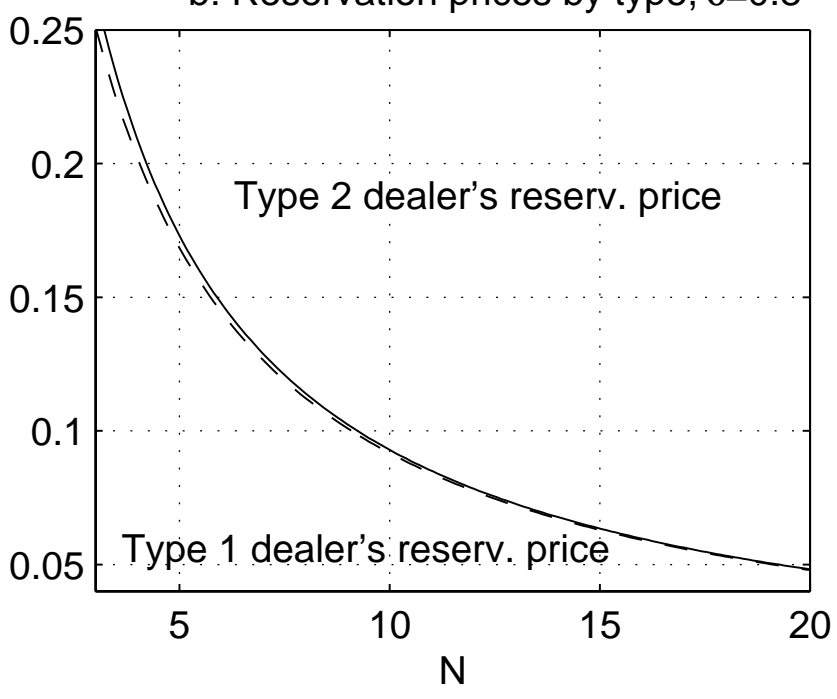

d: Reservation prices by type, $\delta=2$

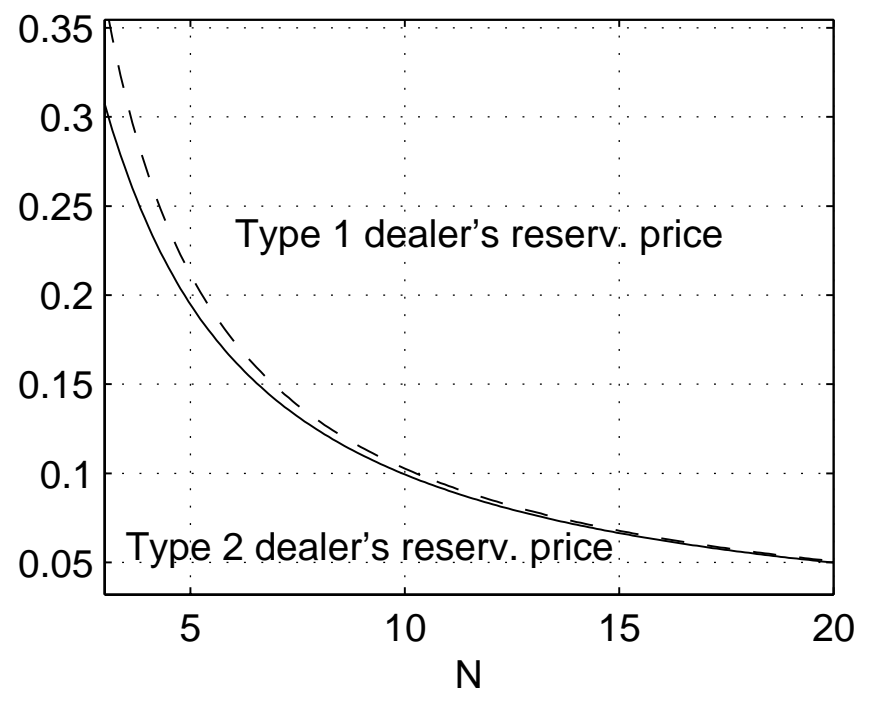




\section{Merger Analysis}

To analyze the effects of a merger between two banks on capital allocation and market-making, we impose restrictions on the model to derive closed-form solutions with which we can perform numerical simulations.

It is assumed that, before a merger, a bank engages in two of three available financial activities. As before, we assume that all banks are engaged in market-making. In addition, each bank chooses one of two activities: project $\mathrm{X}$ or project $\mathrm{Y}$. Hence, banks can be differentiated according to whether they are engaged in project X (Type X banks) or in project $\mathrm{Y}$ (Type Y banks). However, we will impose symmetry between project $\mathrm{X}$ and $\mathrm{Y}$, so that both types of banks will end up allocating the same amount of risk capital towards market-making.

We will analyze a merger assuming that, prior to the merger, all $N+1$ banks have the same capital allocation functions and hence have the same amount of risk capital allocated to marketmaking. This is the case of $N+1$ dealers with identical risk preferences. A merger is then considered between two banks that results in (i) a reduction in the number of firms and hence dealers in the dealership market considered, and, potentially, (ii) the creation of a new type of dealer with a different risk preference from all the other dealers, in which case we have a dealership market with heterogeneous dealers.

\subsection{The stylized model}

Prior to a merger, all banks consist of two divisions, or business lines. Type $\mathrm{X}$ banks are engaged in market-making and project $\mathrm{X}$, while Type $\mathrm{Y}$ banks are engaged in market-making and project $\mathrm{Y}$. We denote the variance and expected return from project $\mathrm{X}$ by $\sigma_{X}^{2}$ and $\mu_{X}\left(\sigma_{X}^{2}\right)$, from project $\mathrm{Y}$ by $\sigma_{Y}^{2}$ and $\mu_{Y}\left(\sigma_{Y}^{2}\right)$, and from market-making by $\sigma_{M}^{2}$ and $\mu_{M}\left(\sigma_{M}^{2}\right)$. We assume that the relationship between the expected return and variance of any particular project's cash flow, $\mu_{j}\left(\sigma_{j}^{2}\right)$, $j \in\{X, Y, M\}$, is increasing and satisfies the Inada conditions. We further restrict the relationship between the expected return and variance to be the same across projects $\mathrm{X}$ and $\mathrm{Y}$ :

$$
\mu_{X}\left(\sigma^{2}\right)=\mu_{Y}\left(\sigma^{2}\right)=\mu\left(\sigma^{2}\right) .
$$


Finally, the correlation between cash flows from projects $\mathrm{X}$ and $\mathrm{Y}$ is denoted by $\rho_{X Y} \in[-1,1]$, the correlation between cash flows from project $\mathrm{X}$ and market-making by $\rho \in[-1,1]$, and the correlation between cash flows from project $\mathrm{Y}$ and market-making by $\rho \in[-1,1]$.

The assumption of symmetry between activities $\mathrm{X}$ and $\mathrm{Y}$ implies that Type $\mathrm{X}$ and Type $\mathrm{Y}$ banks are identical from a risk-return perspective. Hence, each bank allocates the same amount of risk capital to market-making and this results in $N+1$ identical dealers in the dealership market with a risk-aversion coefficient denoted by $\gamma$.

Recall from equation (6) that the first-order conditions for optimality for a bank engaging in set $K$ of financial activities are

$$
\frac{\partial \mu_{j}\left(\hat{\sigma}_{j}^{2}\right)}{\partial \sigma_{j}^{2}}=r \alpha\left[1+\sum_{h \neq j, h \in K} \rho_{h j}\left(\frac{\hat{\sigma}_{h}^{2}}{\hat{\sigma}_{j}^{2}}\right)^{1 / 2}\right], j \in K .
$$

Specializing this condition for our two-division banks yields

$$
\frac{\partial \mu\left(\hat{\sigma}_{X}^{2}\right)}{\partial \sigma_{X}^{2}}=r \alpha\left(1+\rho \frac{\hat{\sigma}_{M}}{\hat{\sigma}_{X}}\right)
$$

and

$$
\frac{\partial \mu_{M}\left(\hat{\sigma}_{M}^{2}\right)}{\partial \sigma_{M}^{2}}=r \alpha\left(1+\rho \frac{\hat{\sigma}_{X}}{\hat{\sigma}_{M}}\right)
$$

for a Type $\mathrm{X}$ bank. The conditions are identical for a Type $\mathrm{Y}$ bank, since $\hat{\sigma}_{Y}=\hat{\sigma}_{X}$, owing to the symmetry assumptions.

\subsection{Effect of a merger on capital allocation}

In this section, we show that a merger between two banks can have ambiguous effects on the risktaking that the merged bank engages in within its various divisions. The results depend on the correlation in cash flow among the different divisions of the newly merged bank, and hence on the types of banks that participate in the merger.

\subsubsection{Merger between two banks of the same type}

Consider a merger between two Type X (or Type Y) banks. By assumption, there are no economies of scale to any of the banking activities considered. We proceed by assuming that the risk-return 
characteristics of all banking activities, represented by the functions $\mu(\cdot)$ and $\mu_{M}(\cdot)$, are unchanged by the merger. ${ }^{11}$ Since the merged bank remains engaged in the same two activities with the same risk-return characteristics as before the merger, and there are no economies of scale present, the merged bank is identical to each of the banks prior to the merger. That is, the merged bank's optimization and capital allocation problem is the same as before. The only change is that there are now $N$ banks instead of $N+1$. This will have an unambiguously negative impact on market quality in the dealership market considered, since the decrease in the number of dealers results in less-efficient risk-sharing than before and hence higher risk premiums charged by dealers, or higher spreads.

Recall that the pre-merger market spread is given by

$$
s=\frac{2 N-1}{N^{2}} \Psi|w|
$$

This is decreasing in $N$ since

$$
\frac{\partial s}{\partial N}=-\frac{2(2 N-1)}{N^{3}} \Psi|w|
$$

\subsubsection{Merger between two banks of different types}

Consider a merger between a Type $\mathrm{X}$ and a Type $\mathrm{Y}$ bank. Assuming that the merged bank retains all three business activities, $\mathrm{M}, \mathrm{X}$, and $\mathrm{Y}$, this merged bank is now different from all the other banks in the economy. The merged bank's market-making activities are now carried out by a dealer who is potentially different from the rest of the dealers in the market. This dealer is denoted as a Type 1 dealer who has a risk-aversion coefficient denoted by $\delta \gamma$.

The risk associated with the merged bank's total cash flow is

$$
\sigma_{p}^{2}=\sigma_{X}^{2}+\sigma_{Y}^{2}+\sigma_{M}^{2}+2 \rho_{X Y} \sigma_{X} \sigma_{Y}+2 \rho\left(\sigma_{X}+\sigma_{Y}\right) \sigma_{M}
$$

The first-order conditions (for an interior optimum) facing the merged bank are simply

$$
\begin{aligned}
& \frac{\partial \mu_{X}\left(\tilde{\sigma}_{X}^{2}\right)}{\partial \sigma_{X}^{2}}-r \alpha\left(1+\rho_{X Y} \frac{\tilde{\sigma}_{Y}}{\tilde{\sigma}_{X}}+\rho \frac{\tilde{\sigma}_{M}}{\tilde{\sigma}_{X}}\right)=0 \\
& \frac{\partial \mu_{Y}\left(\tilde{\sigma}_{Y}^{2}\right)}{\partial \sigma_{Y}^{2}}-r \alpha\left(1+\rho_{X Y} \frac{\tilde{\sigma}_{X}}{\tilde{\sigma}_{Y}}+\rho \frac{\tilde{\sigma}_{M}}{\tilde{\sigma}_{Y}}\right)=0
\end{aligned}
$$

\footnotetext{
${ }^{11}$ These are rather restrictive assumptions, but they are made to focus attention on the economies-of-scope effects from a bank merger.
} 


$$
\frac{\partial \mu_{M}\left(\tilde{\sigma}_{M}^{2}\right)}{\partial \sigma_{M}^{2}}-r \alpha\left(1+\rho \frac{\tilde{\sigma}_{X}}{\tilde{\sigma}_{M}}+\rho \frac{\tilde{\sigma}_{Y}}{\tilde{\sigma}_{M}}\right)=0
$$

The symmetry between activities $\mathrm{X}$ and $\mathrm{Y}$ implies that, at the optimum, $\tilde{\sigma}_{X}^{2}=\tilde{\sigma}_{Y}^{2}$, where the denotes optimal risk levels for the merged bank. The next proposition outlines two factors driving the change in risk-taking by the merged bank in each of its business lines.

Proposition 8 Suppose that a unique solution exists to the capital allocation problem. Then, the merged bank tends to undertake more risk in projects $X$ and $Y$ relative to its pre-merger level $\left(\tilde{\sigma}_{X}^{2}>\hat{\sigma}_{X}^{2}\right):$

(i) the more negatively correlated are the cash flows of division $X$ and the new division $Y$, and

(ii) the more positively correlated are the cash flows from market-making and division $X$ or $Y$ if more risk is undertaken in market-making, or the more negatively correlated are the cash flows from market-making and division $X$ or $Y$ if less risk is undertaken in market-making after the merger.

The merged bank tends to undertake more risk in market-making $\left(\tilde{\sigma}_{M}^{2}>\hat{\sigma}_{M}^{2}\right)$ :

(i) the more negatively correlated are the cash flows from market-making and the new division, $Y$, and

(ii) the more positively correlated are the cash flows from market-making and division $X$ if more risk is undertaken in division $X$ after the merger, or the more negatively correlated are the cash flows from market-making and division $X$ if less risk is undertaken in project $X$ after the merger.

Proof: See Appendix A.3.

A lower (higher) level of risk-taking in any division corresponds to less (more) risk capital being allocated to that division by the merged bank. Finally, since the merged bank's market-making activities are carried out by a Type 1 dealer with a coefficient of risk-aversion given by $\delta \gamma$, the merged bank undertakes more (less) risk in market-making if and only if $\delta<1(\delta>1)$.

Numerical examples for a given functional form for the expected return to each division illustrate the proposition. Suppose that the expected return to risk-taking in each division can be expressed as

$$
\begin{gathered}
\mu_{X}\left(\sigma_{X}^{2}\right)=a_{X}\left(\sigma_{X}^{2}\right)^{b_{X}}, \\
\mu_{M}\left(\sigma_{M}^{2}\right)=a_{M}\left(\sigma_{M}^{2}\right)^{b_{M}} .
\end{gathered}
$$

We find that the following is true: 
(i) The merged firm undertakes more risk in market-making if and only if the cash flow from market-making is (strictly) negatively correlated with cash flows from the other divisions, $X$ and $Y$. If that correlation is zero, there is no change in the level of risk-taking in marketmaking.

(ii) The merged bank undertakes more risk in division $X$ if the cash flows from division $X$ and $Y$ are not too correlated.

Graphs from the numerical examples are shown in Appendix A.4.

\subsection{Effect of a merger on market liquidity}

The impact that a merger between two banks has on market liquidity depends crucially on whether more or less risk capital is allocated to market-making by the merged bank. If the merged bank allocates more capital to market-making, market liquidity can improve. But market liquidity will always deteriorate if the merged bank allocates less capital to market-making.

Prior to the merger, the equilibrium price in the public market is given by (24), or

$$
p^{0}=\frac{(2 N-1) \Psi}{2 N^{2}} w
$$

After the merger, the equilibrium price that prevails depends on whether the Type 1 dealer has a higher $(\delta>1)$ or a lower $(\delta<1)$ risk-aversion. This depends on whether the merged firm allocates more or less risk capital to market-making. If more risk capital is allocated, the Type 1 dealer has a higher risk-bearing capacity and hence $\delta<1$. The reverse is true if the merged firm allocates less risk capital to market-making. From proposition 6 , we know that if $\delta<1$, the new equilibrium price in the public market is given by

$$
p^{m}(\delta<1)=\left\{\left(1-\frac{\beta_{2}}{\bar{\beta}}\right) \frac{\beta_{2}^{2} \Psi_{2}^{2}}{\bar{\beta}}+\frac{\beta_{2}}{2 \bar{\beta}^{2}} \beta_{1}^{2} \Psi_{1}^{2}\left(2-\beta_{2} \Psi_{2}\right)-\frac{\Psi_{2}}{2}\left[1-\left(1-\frac{\beta_{2}}{\bar{\beta}}\right) \beta_{2} \Psi_{2}\right]^{2}\right\} w .
$$

However, if $\delta>1$, the new equilibrium price in the public market is given by

$$
p^{m}(\delta>1)=\left\{\left(1-\frac{\beta_{1}}{\bar{\beta}}\right) \frac{\beta_{1}^{2} \Psi_{1}^{2}}{\bar{\beta}}+\frac{\beta_{1}}{2 \bar{\beta}^{2}} \beta_{2}^{2} \Psi_{2}^{2}\left(2-\beta_{1} \Psi_{1}\right)-\frac{\Psi_{1}}{2}\left[1-\left(1-\frac{\beta_{1}}{\bar{\beta}}\right) \beta_{1} \Psi_{1}\right]^{2}\right\} w .
$$


Proposition 9 Market liquidity improves, in the sense that market spreads are smaller, when $\delta$ is small enough, and the number of dealers in the market is large enough. That is, where values of $\delta<1$ are small enough, a merger improves liquidity for any number of dealers. For intermediate values of $\delta<1$, a merger improves liquidity only if the number of dealers in the market is large enough. For $\delta>1$, a merger always results in a deterioration of liquidity.

Figures 2 and 3 illustrate the proposition. They show that, for any $\delta<1$, there is a critical $N^{*}$ for which liquidity improves if $N>N^{*}$, while liquidity deteriorates if $N<N^{*} . N^{*}(\delta)$ is implicitly defined as the $N$ that solves

$$
p^{0}-p^{m}(\delta)=0
$$

where $p^{0}$ and $p^{m}(\delta)$ are defined by equations (24), (43), and (44). For small values of $\delta$, this critical $N^{*}$ is negative. For intermediate values of $\delta<1$, this critical $N^{*}$ becomes positive (and finite) and increases with $\delta$. For $\delta>1$, however, $N^{*} \rightarrow \infty$.

As stated at the beginning of this section, the merger that we consider between two banks has the following consequences: (i) a reduction in the total number of dealers in the dealership market, and (ii) the creation of a new type of dealer with a different risk preference from all the other dealers (a Type 1 dealer and $\mathrm{N}$ Type 2 dealers). The first effect reduces the efficiency of risk-sharing among dealers in the market. As we have already argued, risk-sharing is inefficient in this market because of imperfect competition among dealers. That is, the efficiency of risk-sharing increases with the number of dealers in the market and tends towards first-best as the number of dealers tend towards infinity. Hence, a reduction in the number of dealers will have a negative impact on market prices and spreads.

The second effect induces a change in the risk-bearing capacity of the market, since there is a change in the risk preference of one dealer, the newly created Type 1 dealer. If the Type 1 dealer has a larger capacity for bearing risk (that is, a lower risk-aversion parameter, or $\delta<1$ ), the second consequence of a merger has a positive impact on market price and spreads. In this case, the net impact of a merger on market prices and spreads is ambiguous. If the Type 1 dealer has a smaller capacity for bearing risk $(\delta>1)$, the second consequence of the merger has a negative impact on market prices and spreads. In this case, the net impact of a merger on prices and spreads is negative. 
When the Type 1 dealer has a larger risk-bearing capacity, $\delta<1$, the two consequences of the merger as outlined have offsetting effects. The greater the increase in the Type 1 dealer's ability to bear risk (or, the smaller the $\delta$ ), the more important the impact of the increased risk-bearing capacity in the market. Moreover, the larger the number of dealers in the market to start with $(N)$, the less important the reduction in the efficiency of risk-sharing from a merger. Hence, for any $\delta<1$, the larger $N$ is, the more likely the merger is to improve market liquidity. As well, for any $N$, the smaller $\delta<1$ is, the more likely the merger is to improve market liquidity. 
Figure 2: Equilibrium prices before and after a merger, $\delta<1$

a: Equilibrium price (spread), $\delta=0.2$

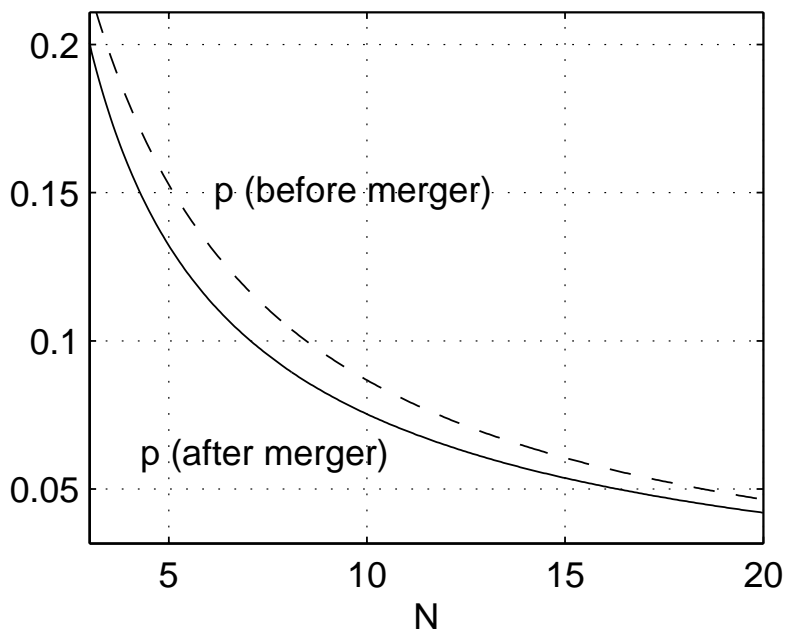

c: Equilibrium price (spread), $\delta=0.45$

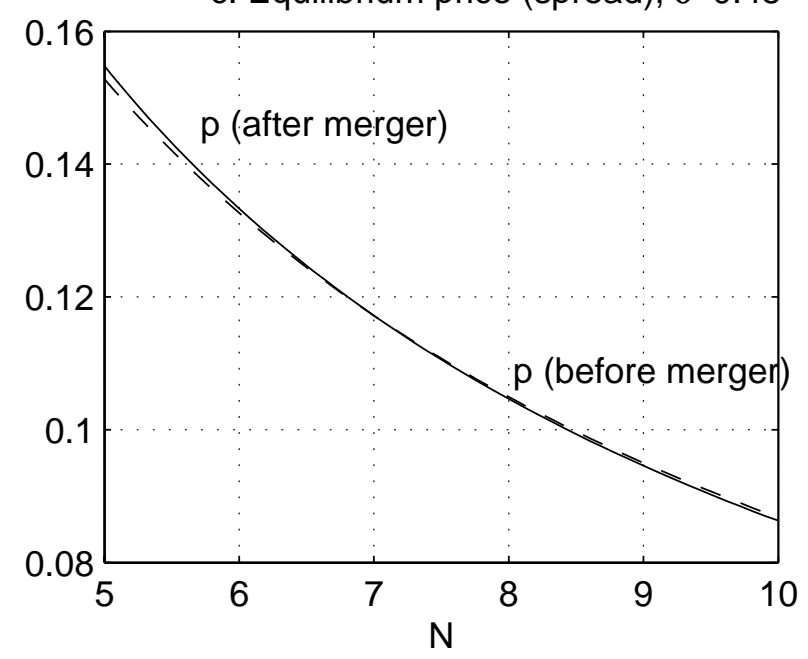

b: Equilibrium price (spread), $\delta=0.4$

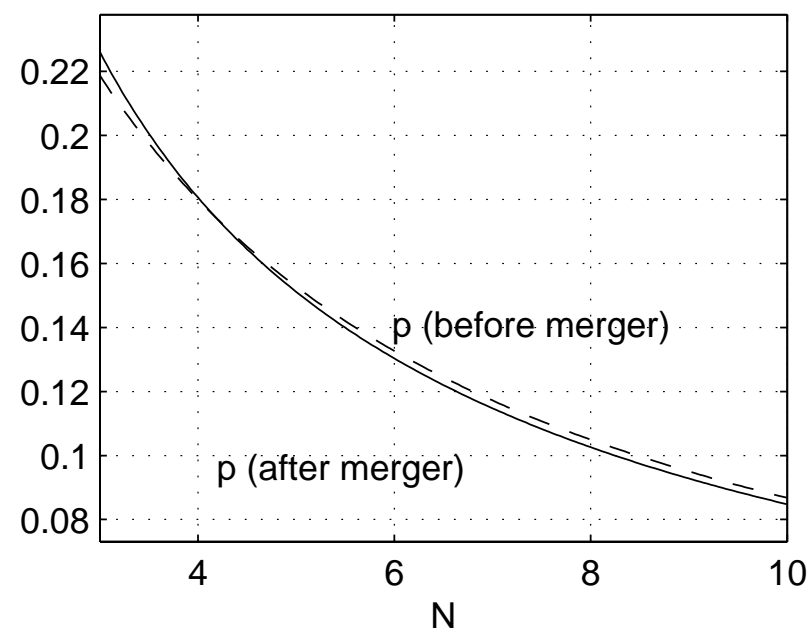

d: Equilibrium price (spread), $\delta=0.6$

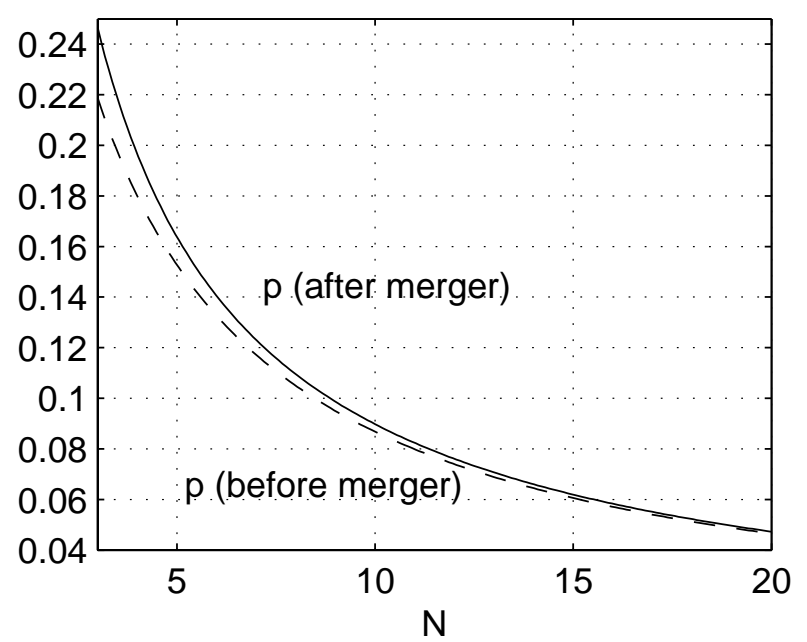


Figure 3: Equilibrium prices before and after a merger, $\delta>1$

a: Equilibrium price (spread), $\delta=1.2$

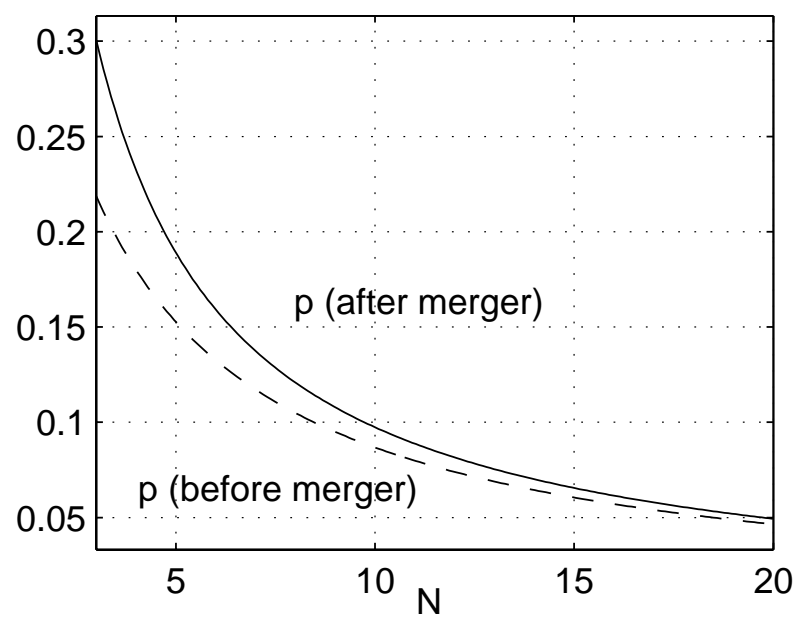

c: Equilibrium price (spread), $\delta=1.7$

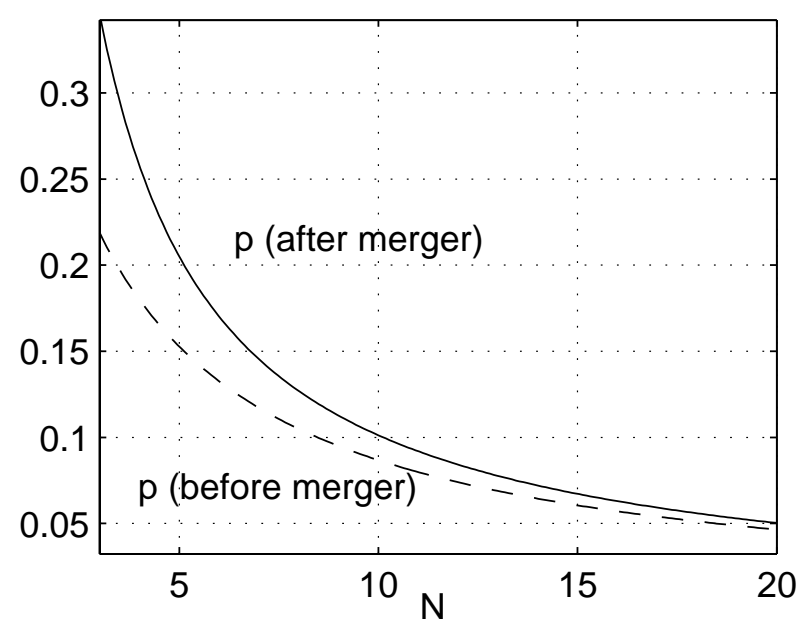

b: Equilibrium price (spread), $\delta=1.5$

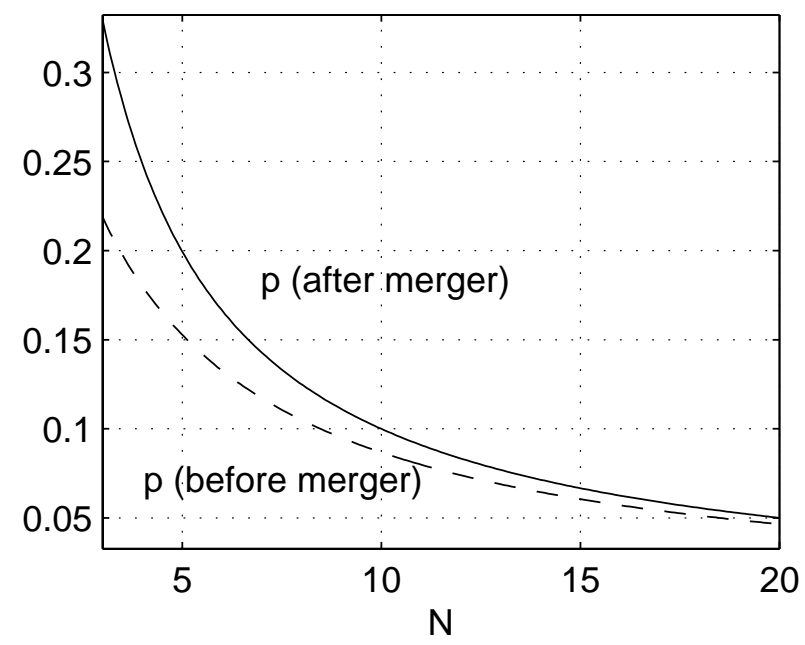

d: Equilibrium price (spread), $\delta=2$

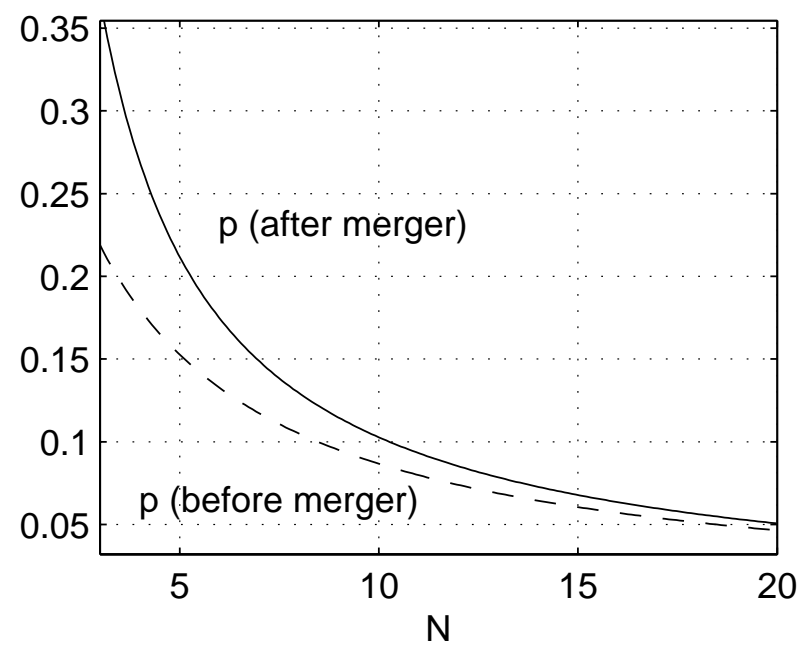




\section{Conclusion}

This paper has bridged together two topics in financial economics that until now have evolved as separate areas of research: market microstructure models and capital allocation decision-making within financial institutions. This is a first step towards consolidating advances made in the individual fields of study, and it provides a useful framework within which to understand how financial institutions and markets are interrelated through the interaction of the risk management of institutions and the risk-bearing capacity of markets.

Although there are many possible applications for the framework we have introduced, this paper has focused on the impact that finanical market consolidation has on liquidity in dealership markets. Liquidity was characterized by bid-ask spreads in a model of inter-dealer trading that has been extended to allow for heterogeneity among dealers. The impact on market-making behaviour from a change in the allocation of capital across bank divisions was explicitly modelled, which enabled us to characterize the potential effects of financial market consolidation on dealership markets, such as foreign exchange and government securities markets.

We found that a merger of two banks can lead to increased market liquidity in dealership markets, even in highly concentrated markets, if the merger results in a sufficient increase in the risk-bearing capacity of the market. The risk-bearing capacity of the dealership market, in turn, depends on how capital allocation in a financial institution is affected by the merger. This depends on the correlation among cash flows from business activities that the newly merged financial institution engages in. A negative correlation between market-making and the new activities of a merged firm suggests the possibility of increased market liquidity. Our results suggest that, when faced with a proposed merger between financial institutions, policy-makers and regulators would want to examine the correlations among division cash flows. 


\section{Bibliography}

Froot, K.A. and J.C. Stein. 1998. "Risk Management, Capital Budgeting, and Capital Structure Policy for Financial Institutions: An Integrated Approach." Journal of Financial Economics 47: $55-82$.

Gravelle, T. 1999. "Markets for Government of Canada Securities in the 1900s: Liquidity and Cross-Country Comparisons." Bank of Canada Review (Autumn): 9-18.

. 2001. "The Economics of Market Liquidity and Transparency in Dealership Markets." Mimeo, Bank of Canada.

Ho, T.S.Y. and H.R. Stoll. 1983. "The Dynamics of Dealer Markets Under Competition.” Journal of Finance 38: 1053-74.

James, C. 1996. "RAROC Based Capital Budgeting and Performance Evaluation: A Case Study of Bank Capital Allocation." Working Paper No. 96-40, The Wharton School, University of Pennsylvania.

Kyle, A.S. 1989. "Informed Speculation with Imperfection Competition." Review of Economic Studies 56: 317-55.

Madhavan, A. 2000. "Market Microstructure: A Survey." Journal of Financial Markets 3: 205-58.

O’Hara, M. 1995. Market Microstructure Theory. Basil Blackwell, Cambridge, Massachusetts.

Perold, A.F. 2001. "Capital Allocation in Financial Firms." Working Paper No. 98-072, Harvard Business School.

Stoughton, N.M. and J. Zechner. 1999. "Optimal Capital Allocation Using RAROC and EVA." Mimeo, UC Irvine and University of Vienna.

. 2000. "The Dynamics of Capital Allocation." Mimeo, UC Irvine and University of Vienna.

Volger, K.-H. 1997. "Risk Allocation and Inter-Dealer Trading." European Economic Review 41: 1615-34. 


\section{Appendix A}

\section{A.1 Proof of Proposition 1}

The first-order condition (for an interior optimum) to division $j$ 's problem is

$$
\frac{\partial \mu_{j}\left(\sigma_{j}^{2}\right)}{\partial \sigma_{j}^{2}}=r \frac{\partial T_{j}\left(\sigma_{j}^{2}\right)}{\partial \sigma_{j}^{2}}, j \in K .
$$

To induce the first-best choice of $\sigma_{j}^{2}$ at the division level, the bank's risk manager has to choose a capital allocation function, $T_{j}$, so that, at the optimal risk level for the division,

$$
\frac{\partial T_{j}\left(\hat{\sigma}_{j}^{2}\right)}{\partial \sigma_{j}^{2}}=\alpha\left[1+\sum_{h \neq j, h \in K} \rho_{h j}\left(\frac{\hat{\sigma}_{h}^{2}}{\hat{\sigma}_{j}^{2}}\right)^{1 / 2}\right] .
$$

Integrating over $\sigma_{j}^{2}$ yields the optimal capital allocation functions

$$
T_{j}\left(\sigma_{j}^{2}\right)=\alpha\left[1+\sum_{h \neq j, h \in K} \rho_{h j}\left(\frac{\hat{\sigma}_{h}^{2}}{\hat{\sigma}_{j}^{2}}\right)^{1 / 2}\right] \sigma_{j}^{2}, j \in K .
$$

The salary component of the division managers' compensation, $S_{j}$, is chosen so that managers obtain at least their reservation utility, $\underline{U}_{j}$,

$$
S_{j}=\underline{U}_{j}-\tau\left[\mu\left(\hat{\sigma}_{j}^{2}\right)-r T_{j}\left(\hat{\sigma}_{j}^{2}\right)\right]
$$

If we define $\gamma_{j}$ such that

$$
\gamma_{j}=r \alpha\left[1+\sum_{h \neq j, h \in K} \rho_{h j}\left(\frac{\hat{\sigma}_{h}^{2}}{\hat{\sigma}_{j}^{2}}\right)^{1 / 2}\right], j \in K,
$$

we can rewrite the objective function of the manager of division $j$ as

$$
\max _{\sigma_{j}^{2}} \mu_{i}\left(\sigma_{j}\right)-\frac{\gamma_{j}}{2} \sigma_{j}^{2}
$$

Hence, the optimal capital allocation function induces the (otherwise risk-neutral) manager of division $j$ to behave like a risk-averse agent with an exponential utility function and risk-aversion parameter $\gamma_{j}$ with a net payoff of $\mu_{j}\left(\sigma_{j}^{2}\right) .{ }^{12}$

\footnotetext{
${ }^{12}$ For a risk-averse manager with a risk-aversion parameter $\lambda$ who maximizes $U_{j}-\frac{\lambda}{2} \operatorname{var}\left(U_{j}\right) \equiv \mu_{j}-r T_{j}-\frac{\tau \lambda}{2} \sigma_{j}^{2}$, the capital allocation function is:

$$
T_{j}\left(\sigma_{j}^{2}\right)=\left\{\alpha\left[1+\sum_{h \neq j, h \in K} \rho_{h j}\left(\frac{\sigma_{h}^{2}}{\sigma_{j}^{2}}\right)^{1 / 2}\right]+\frac{\tau \lambda}{2}\right\} \sigma_{h}^{2} .
$$
}




\section{A.2 Proof of Proposition 2}

Dealers take into account the effect that their trades will have on the equilibrium inter-dealer price when they determine their trading strategies. A dealer's strategy is an excess demand function. These functions are communicated to the inter-dealer broker, which chooses a market-clearing price. By changing the excess demand function they send to the interdealer broker, dealers can change the equilibrium price. Therefore, dealers have the incentive to restrict the quantities they trade compared with the competitive level, since they are trading against an upward-sloping residual supply curve.

Consider the problem of Dealer $i$. Market clearing implies that $x_{i}+\sum_{j \neq i} \alpha-\beta p_{d}+\mu w_{j}=0$, or

$$
p_{d}=\frac{x_{i}+N \alpha+\mu \sum_{j \neq i} w_{j}}{N \beta}
$$

The assumptions that the market-clearing price and the investor's order do not convey any information and are normally distributed random variables along with an exponential utility imply that maximizing the expected utility of profits is equivalent to maximizing the certainty equivalent, given by $E\left[\pi_{i}\right]-\frac{\Psi}{2} \operatorname{var}\left(\pi_{i}\right)$, or,

$$
\left(x_{i}-w_{i}\right) E[v]+p w_{i}-p_{d} x_{i}-\frac{\Psi}{2}\left(x_{i}-w_{i}\right)^{2} .
$$

The first-order condition with respect to $x_{i}$ yields

$$
-p_{d}-\frac{\partial p_{d}}{\partial x_{i}} x_{i}-\Psi\left(x_{i}-w_{i}\right)=-p_{d}-\frac{x_{i}}{N \beta}-\Psi\left(x_{i}-w_{i}\right)=0,
$$

or

$$
x_{i}=\frac{N \beta\left(-p_{d}+\Psi w_{i}\right)}{1+\Psi N \beta} .
$$

Equating coefficients yields the desired results.

\section{A.3 Proof of Proposition 8}

The pre-merger problem for a bank is as follows:

$$
\max _{\sigma_{M}^{2}, \sigma_{X}^{2}} \mu_{M}\left(\sigma_{M}^{2}\right)+\mu_{X}\left(\sigma_{X}^{2}\right)-r \alpha\left[\sigma_{M}^{2}+\sigma_{X}^{2}+2 \rho \sigma_{M} \sigma_{X}\right] .
$$


The first-order conditions are

$$
\begin{aligned}
& \mu_{M}^{\prime}\left(\hat{\sigma}_{M}^{2}\right)=r \alpha\left[1+\rho \frac{\hat{\sigma}_{X}}{\hat{\sigma}_{M}}\right] \\
& \mu_{X}^{\prime}\left(\hat{\sigma}_{X}^{2}\right)=r \alpha\left[1+\rho \frac{\hat{\sigma}_{M}}{\hat{\sigma}_{X}}\right] .
\end{aligned}
$$

Note that $\mu_{M}\left(\sigma_{M}^{2}\right)$ is a function of $\sigma_{M}^{2}$ only and $\mu_{X}\left(\sigma_{X}^{2}\right)$ is a function of $\sigma_{X}^{2}$ only.

Now, we turn to the merged bank's problem:

$$
\max _{\sigma_{M}^{2}, \sigma_{X}^{2}, \sigma_{Y}^{2}} \mu_{M}\left(\sigma_{M}^{2}\right)+\mu_{X}\left(\sigma_{X}^{2}\right)+\mu_{Y}\left(\sigma_{Y}^{2}\right)-r \alpha\left[\sigma_{M}^{2}+\sigma_{X}^{2}+\sigma_{Y}^{2}+2 \rho \sigma_{M}\left(\sigma_{X}+\sigma_{Y}\right)+2 \rho_{X Y} \sigma_{X} \sigma_{Y}\right] .
$$

Taking derivatives with respect to $\sigma_{M}^{2}, \sigma_{X}^{2}$, and $\sigma_{Y}^{2}$ yields

$$
\begin{gathered}
\mu_{M}^{\prime}\left(\sigma_{M}^{2}\right)-r \alpha\left[1+\frac{\rho \sigma_{X}+\rho \sigma_{Y}}{\sigma_{M}}\right] \equiv D_{M}\left(\sigma_{M}^{2} \mid \sigma_{X}^{2}, \sigma_{Y}^{2}\right) \\
\mu_{X}^{\prime}\left(\sigma_{X}^{2}\right)-r \alpha\left[1+\frac{\rho_{X Y} \sigma_{Y}+\rho \sigma_{M}}{\sigma_{X}}\right] \equiv D_{X}\left(\sigma_{X}^{2} \mid \sigma_{M}^{2}, \sigma_{Y}^{2}\right) \\
\mu_{Y}^{\prime}\left(\sigma_{Y}^{2}\right)-r \alpha\left[1+\frac{\rho_{X Y} \sigma_{X}+\rho \sigma_{M}}{\sigma_{Y}}\right] \equiv D_{Y}\left(\sigma_{Y}^{2} \mid \sigma_{M}^{2}, \sigma_{X}^{2}\right) .
\end{gathered}
$$

Post-merger optimum $\left(\tilde{\sigma}_{M}^{2}, \tilde{\sigma}_{X}^{2}=\tilde{\sigma}_{Y}^{2}\right)$ is implicitly defined by

$$
D_{M}\left(\tilde{\sigma}_{M}^{2} \mid \tilde{\sigma}_{X}^{2}\right)=D_{X}\left(\tilde{\sigma}_{X}^{2} \mid \tilde{\sigma}_{M}^{2}\right)=0
$$

Now, consider the function

$$
D_{M}\left(z \mid \tilde{\sigma}_{X}^{2}\right)=\mu_{M}^{\prime}(z)-r \alpha\left[1+\frac{\rho \tilde{\sigma}_{X}+\rho \tilde{\sigma}_{Y}}{z^{1 / 2}}\right]
$$

Note that we have taken $\tilde{\sigma}_{X}=\tilde{\sigma}_{Y}$ as (fixed) parameters. This defines a function in $z$ that we know is decreasing in $z$ (from the existence and uniqueness of the solution to the merged bank's problem). We also know that, evaluated at $z=\tilde{\sigma}_{M}^{2}$, the function is equal to zero.

Therefore, for a value $z=z^{\prime}, D_{M}\left(z^{\prime} \mid \tilde{\sigma}_{X}^{2}\right)<0$ implies that $z^{\prime}>\tilde{\sigma}_{M}^{2}$ and $D_{M}\left(z^{\prime} \mid \tilde{\sigma}_{X}^{2}\right)>0$ implies that $z^{\prime}<\tilde{\sigma}_{M}^{2}$. Since we are interested in comparing $\hat{\sigma}_{M}^{2}$ with $\tilde{\sigma}_{M}^{2}$, we want to know whether the function $D_{M}\left(z \mid \tilde{\sigma}_{X}^{2}\right)$ evaluated at $z=\hat{\sigma}_{M}^{2}$ is positive or negative:

$$
D_{M}\left(\hat{\sigma}_{M}^{2} \mid \tilde{\sigma}_{X}^{2}\right)=\mu_{M}^{\prime}\left(\hat{\sigma}_{M}^{2}\right)-r \alpha\left[1+\frac{\rho \tilde{\sigma}_{X}+\rho \tilde{\sigma}_{Y}}{\hat{\sigma}_{M}}\right]
$$


From equation (2), we can substitute $r \alpha\left[1+\rho \frac{\hat{\sigma}_{X}}{\hat{\sigma}_{M}}\right]$ for $\mu_{M}^{\prime}\left(\hat{\sigma}_{M}^{2}\right)$. (Remember that $\mu_{M}^{\prime}\left(\sigma_{M}^{2}\right)$ does not depend on $\sigma_{X}^{2}$ or $\sigma_{Y}^{2}$.) So the above works out to

$$
D_{M}\left(\hat{\sigma}_{M}^{2} \mid \tilde{\sigma}_{X}^{2}\right)=-r \alpha\left[\frac{\rho\left(\tilde{\sigma}_{X}-\hat{\sigma}_{X}\right)+\rho \tilde{\sigma}_{Y}}{\hat{\sigma}_{M}}\right]
$$

The same can be done for project $\mathrm{X}$ to obtain

$$
D_{X}\left(\hat{\sigma}_{X}^{2} \mid \tilde{\sigma}_{M}^{2}\right)=-r \alpha\left[\frac{\rho_{X Y} \tilde{\sigma}_{Y}+\rho\left(\tilde{\sigma}_{M}-\hat{\sigma}_{M}\right)}{\hat{\sigma}_{X}}\right]
$$

Expression (63) is more likely to be positive if $\rho_{X Y}$ is negative and large in absolute value. That is, post-merger risk-taking in division $X$ is influenced by the correlation of its cash flow with division $Y$ 's cash flow. In addition, it is also more likely to be positive when $\rho$ is negative if $\tilde{\sigma}_{M}-\hat{\sigma}_{M}>0$ and vice versa. That is, post-merger risk-taking in division $X$ is also influenced by the correlation of its cash flow with market-making and by what happens to the risk-taking level in market-making as a result of the merger. The net effect on $\sigma_{X}^{2}$ of the merger, of course, depends on the combination of the two effects. The same analysis can be made for market-making: expression (62) is positive if $\rho\left(2 \tilde{\sigma}_{X}-\hat{\sigma}_{X}\right)<0$ and negative if the reverse is true.

\section{A.4 Numerical examples}

For return functions characterized by

$$
\begin{gathered}
\mu_{X}\left(\sigma_{X}^{2}\right)=a_{X}\left(\sigma_{X}^{2}\right)^{b_{X}}, \\
\mu_{M}\left(\sigma_{M}^{2}\right)=a_{M}\left(\sigma_{M}^{2}\right)^{b_{M}},
\end{gathered}
$$

we obtain the following results with the parameter values: $a_{X}=1.5, a_{M}=1, b_{X}=b_{M}=1 / 3$, $r=0.1$, and $\alpha=0.05$. Changing the parameters does not affect the results. 
Figure A.1: Risk-taking in market-making
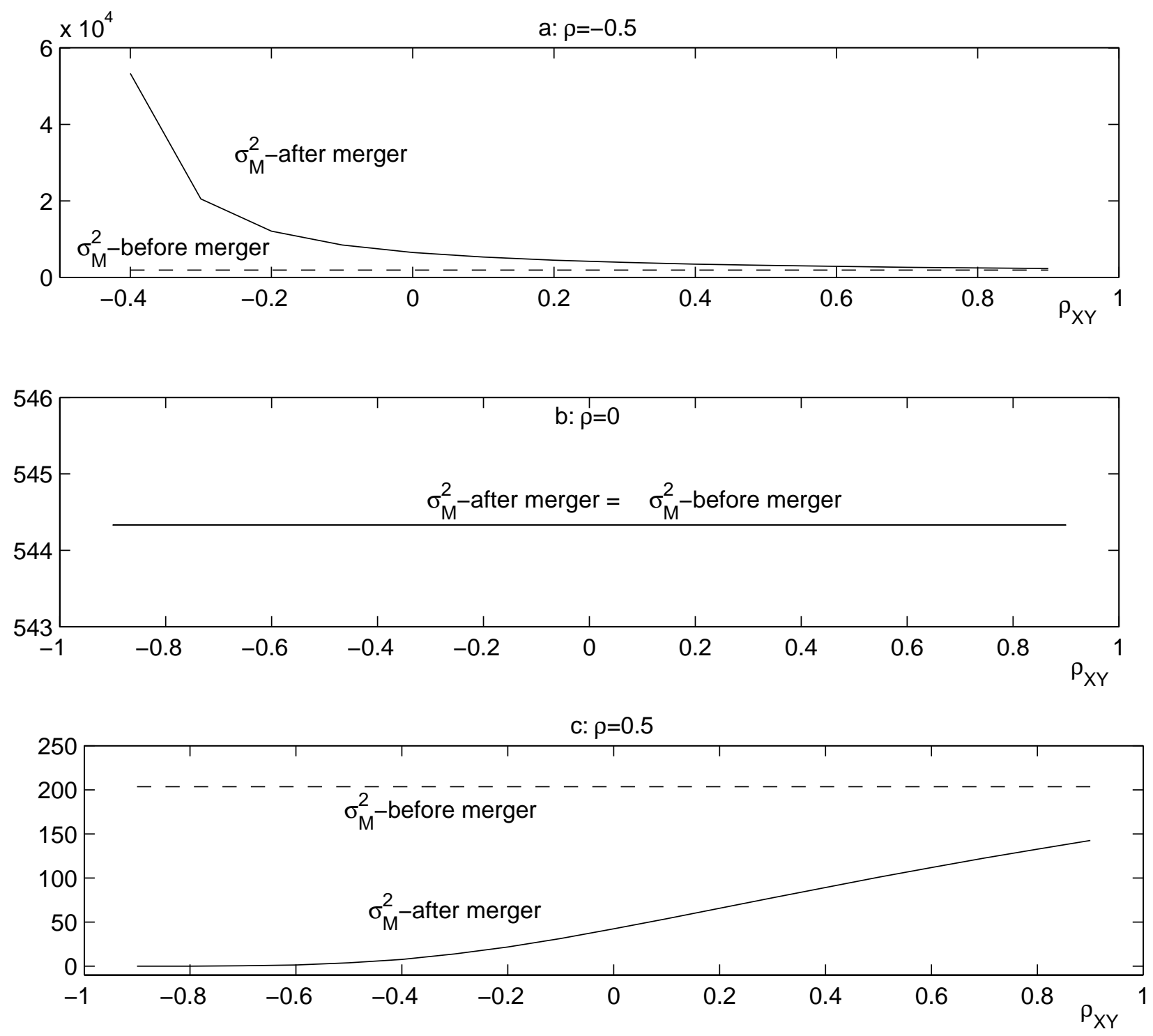
Figure A.2: Risk-taking in division $\mathrm{X}$
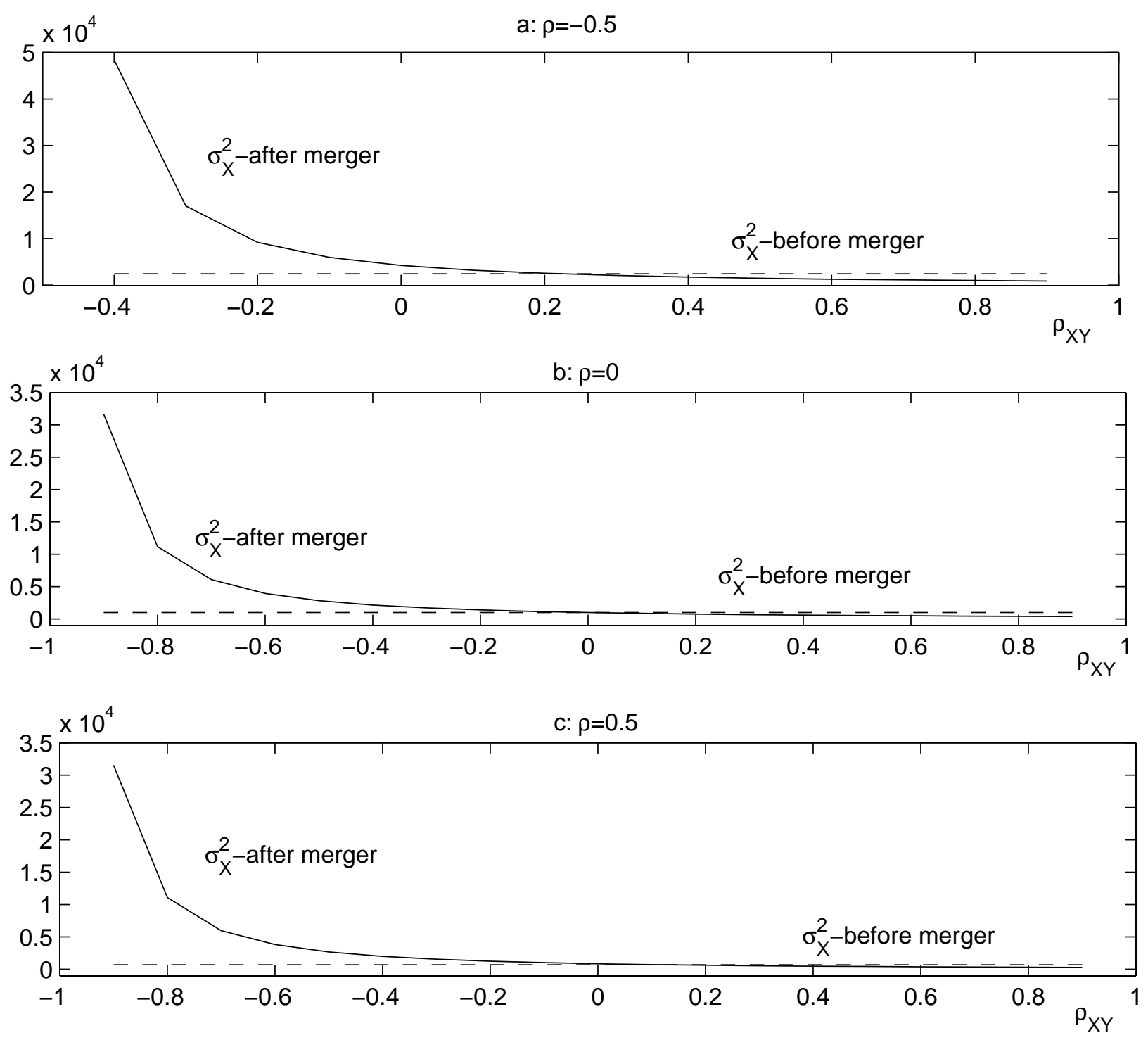
Figure A.3: Risk-taking in market-making

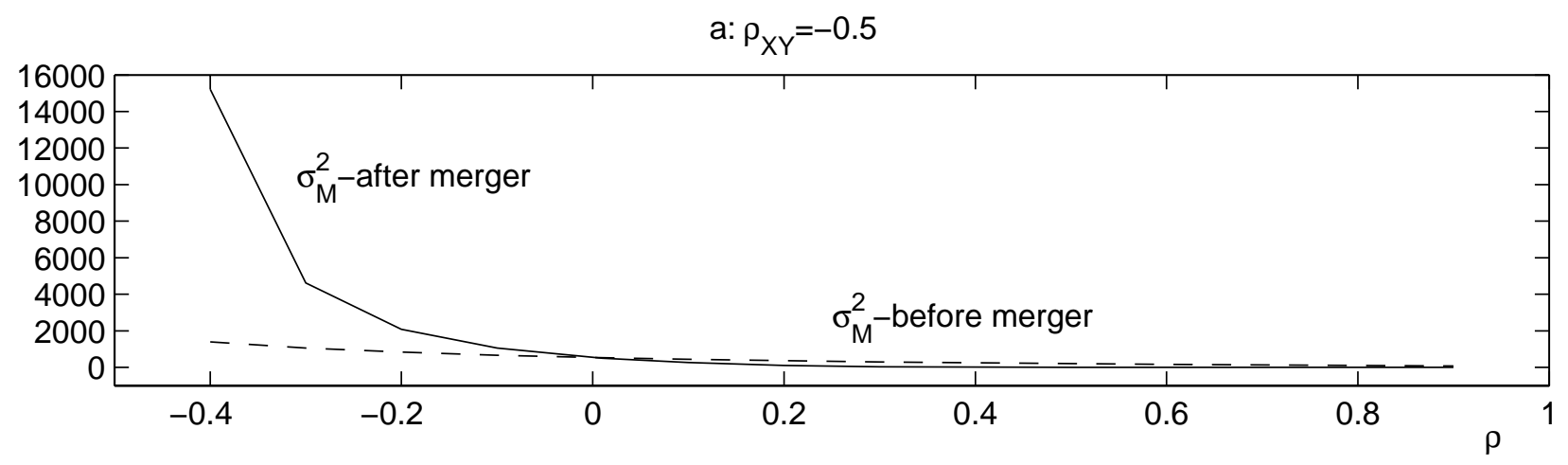

b: $\rho_{X Y}=0$

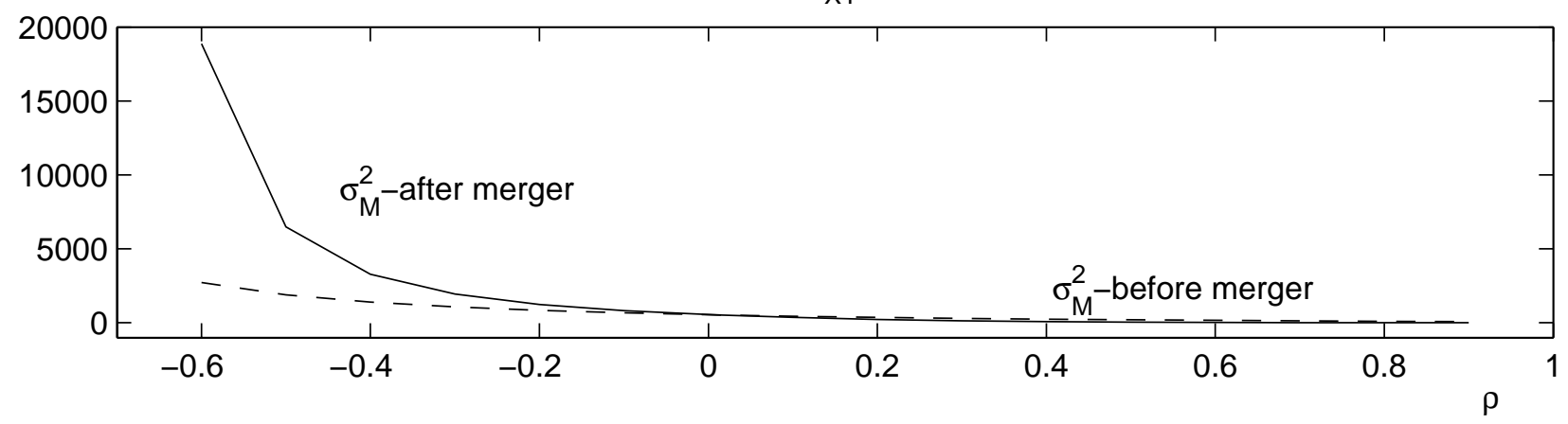

c: $\rho_{X Y}=0.5$

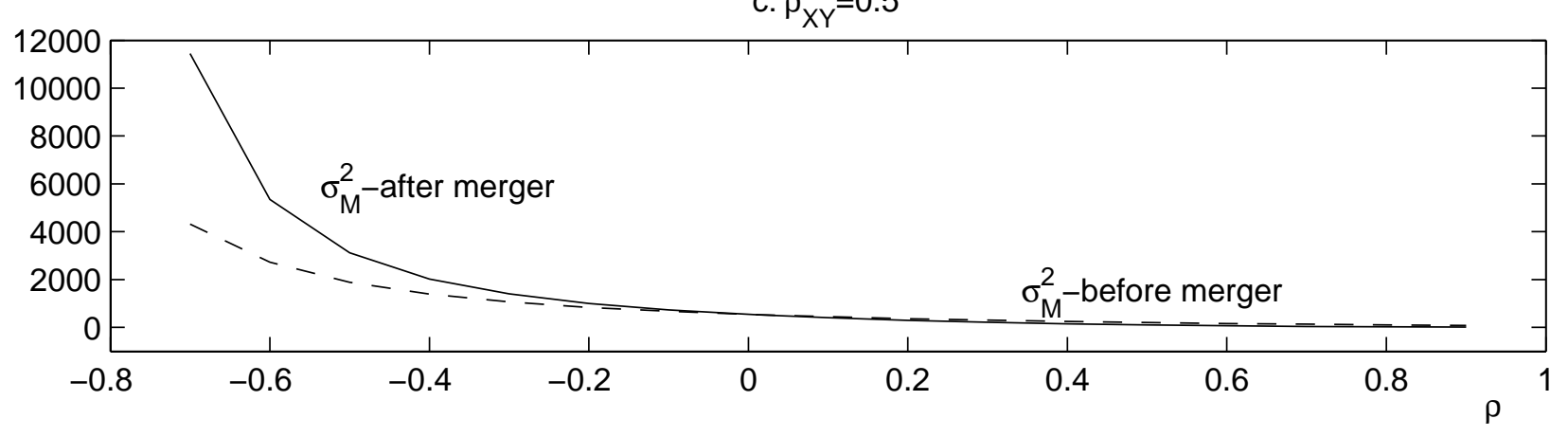


Figure A.4: Risk-taking in division $\mathrm{X}$
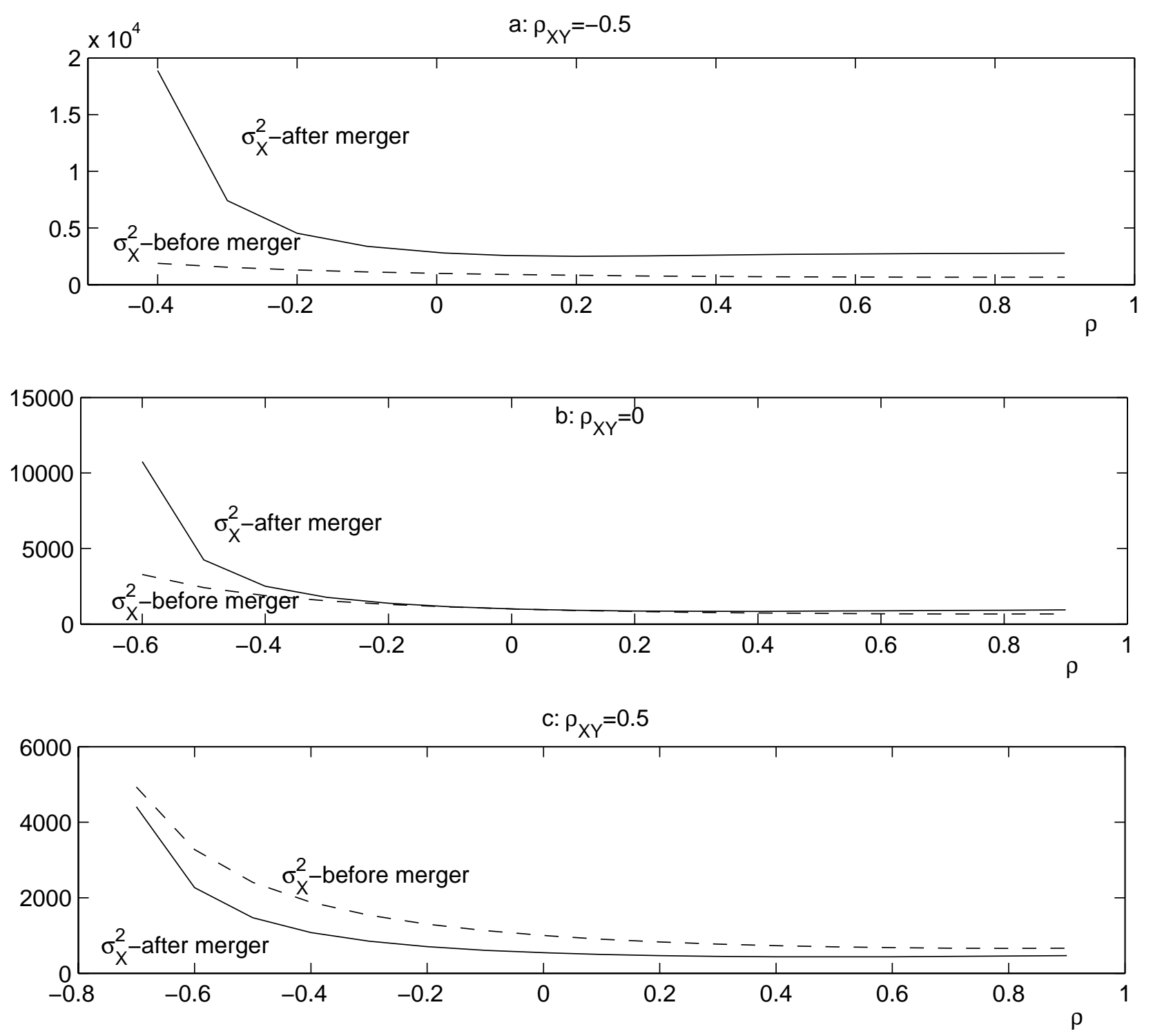


\section{Bank of Canada Working Papers \\ Documents de travail de la Banque du Canada}

Working papers are generally published in the language of the author, with an abstract in both official languages. Les documents de travail sont publiés généralement dans la langue utilisée par les auteurs; ils sont cependant précédés d'un résumé bilingue.

2002

2002-4 Does Micro Evidence Support the Wage Phillips Curve in Canada?

J. Farès

2002-3 An Introduction to Wavelets for Economists

C. Schleicher

2002-2 Asset Allocation Using Extreme Value Theory

Y. Bensalah

2002-1

Taylor Rules in the Quarterly Projection Model

J. Armour, B. Fung, and D. Maclean

2001

2001-27 The Monetary Transmission Mechanism at the Sectoral Level

J. Farès and G. Srour

2001-26 An Estimated Canadian DSGE Model with

Nominal and Real Rigidities

A. Dib

2001-25

New Phillips Curve with Alternative Marginal Cost Measures

for Canada, the United States, and the Euro Area

E. Gagnon and H. Khan

2001-24 Price-Level versus Inflation Targeting in a Small Open Economy

G. Srour

2001-23 Modelling Mortgage Rate Changes with a

Smooth Transition Error-Correction Model

Y. Liu

2001-22

On Inflation and the Persistence of Shocks to Output

M. Kichian and R. Luger

2001-21 A Consistent Bootstrap Test for Conditional Density

Functions with Time-Dependent Data

F. Li and G. Tkacz

2001-20 The Resolution of International Financial Crises:

Private Finance and Public Funds

A. Haldane and M. Kruger

2001-19 Employment Effects of Restructuring in the Public

Sector in North America

P. Fenton, I. Ip, and G. Wright

2001-18 Evaluating Factor Models: An Application to

Forecasting Inflation in Canada

M.-A. Gosselin and G. Tkacz

2001-17 Why Do Central Banks Smooth Interest Rates?

G. Srour

2001-16 Implications of Uncertainty about Long-Run

Inflation and the Price Level

G. Stuber

Copies and a complete list of working papers are available from:

Pour obtenir des exemplaires et une liste complète des documents de travail, prière de s'adresser à :

Publications Distribution, Bank of Canada

234 Wellington Street, Ottawa, Ontario K1A 0G9

E-mail: publications@bankofcanada.ca

Web site: http://www.bankofcanada.ca
Diffusion des publications, Banque du Canada 234, rue Wellington, Ottawa (Ontario) K1A 0G9 Adresse électronique : publications@banqueducanada.ca Site Web : http://www.banqueducanada.ca 